\title{
Suicídio e violência estrutural. Revisão sistemática de uma correlação marcada pelo colonialismo
}

\author{
Izabel Weber* \\ Cristiano Gianolla** \\ \& Luciana Sotero***
}

Resumo: O suicídio é a última das causas externas de morte (CE) (que incluem homicídios e acidentes) a apresentar concentração de casos (80\%) em países de baixa e média renda. Há literatura consolidada identificando a violência estrutural como determinante para as CE, mas pouca quanto ao suicídio. O objetivo deste artigo é definir novo marco teórico para o estudo do suicídio como fenômeno social, onde a interação social reflete as marcas do colonialismo. Foram analisados os dados sobre mortalidade do Institute for Health Metrics and Evaluation (IHME), Seattle, Washington, e realizada revisão sistemática da literatura sobre suicídio, violência estrutural, colonialismo, democracia e desenvolvimento, entre 1968 a 2018, seguindo a metodologia Prisma. Centrada na teoria crítica, adotou-se a determinação social como categoria básica para a identificação dos reflexos do colonialismo nos determinantes que caracterizam o perfil epidemiológico do suicídio, tornando possível seu enquadramento como uma "patologia do poder". Dos dados estatísticos e da revisão sistemática, foram identificados os grupos de risco para o suicídio - os mais afetados pela assimetria de poder, oriunda do colonialismo - mesmo em países de alta renda.

Palavras-chave: Suicídio. Violência. Colonialismo. Democracia. Revisão sistemática.

\section{Suicide and structural violence. Systematic review of a correlation marked by colonialism}

Abstract: Suicide is the last of the external causes of death (EC) to have a concentration of cases (80\%) in low- and middle-income countries. There is a consolidated literature identifying structural violence as a determinant for EC, but little regarding suicide. The aim of this paper is to define a new theoretical framework for the study of suicide as a social phenomenon, where social interaction reflects the hallmarks of colonialism. The mortality data from Institute for Health Metrics and Evaluation (IHME), Seattle, Washington, were analyzed and a systematic review of the literature on suicide, structural violence, colonialism, democracy and development, covering the period 1968 and 2018, was conducted based on Prisma methodology. Centered on critical theory, social determination was adopted as basic category for the identification of the reflexes of colonialism in the determinants of epidemiological profile of suicide, making possible its framing as a "pathology of power". Statistical data and a systematic review identified the risk groups for suicide - those most affected by the asymmetry of power arising from colonialism - even in high-income countries.

Keywords: Suicide. Violence. Colonialism. Democracy. Systematic review.

\author{
* Izabel Weber \\ é gestora em \\ políticas públicas \\ e doutoranda em \\ ciência política no \\ Programa Conjunto \\ de Doutoramento \\ entre o Centro de \\ Estudos Sociais (CES) \\ e a Faculdade de \\ Economia (Feuc), \\ da Universidade \\ de Coimbra (UC), \\ "Democracia no \\ Século XXI", Coimbra, \\ Portugal. \\ Orcid: 0000-0001- \\ 6984-3725 \\ <izabelweber@ces. \\ uc.pt>. \\ **Cristiano Gianolla \\ é pesquisador do \\ Centro de Estudos \\ Sociais (CES) da \\ Universidade de \\ Coimbra. Os seus \\ interesses de \\ investigação estão \\ na interseção \\ de estudos \\ interculturais, da \\ democratização \\ e pós-coloniais. \\ Atualmente integra a \\ equipe de pesquisa \\ do projeto Echoes \\ (H2020) e escreveu \\ dois livros e vários \\ artigos científicos. \\ Orcid: 0000-0002- \\ 2809-0453. \\ <cgianolla@ces. \\ uc.pt>.

\footnotetext{
*** Luciana Sotero é doutora em psicologia clínica pelas Universidades de Coimbra e Lisboa; professora auxiliar convidada
} 
da Faculdade de Psicologia e de Ciências da Educação da Universidade de Coimbra (Fpce/UC), Coimbra, Portugal; investigadora do CES/ Feuc/UC e autora de diversos artigos científicos. Orcid: 0000-00018393-2775.

<lucianasotero@ces. uc.pt>.

\section{Introdução}

$\square$ e acordo com a Organização Mundial da Saúde (OMS), o suicídio é considerado um grave problema de saúde pública, por ser uma das principais causas de mortalidade em escala global, nacional ou local, independentemente do elemento de corte - como gênero, idade, condição socioeconômica, localização geográfica e demais elementos diferenciadores (Nock et alii, 2008; WHO, 2014b).

Na área de saúde pública, onde os problemas de saúde são observados com base na população afetada, diversos estudos apontaram para um significativo aumento dos casos de morte por suicídio desde 1950 (Bertolote \& De Leo, 2012; Bertolote \& Fleischmann, 2002; Hoven et alii, 2010; Pompili, 2012; Turecki \& Brent, 2016), mas poucos trabalhos empíricos versaram sobre a recente tendência de concentração em países de baixa e média renda (Bantjes et alii, 2016; lemmi et alii, 2016).

Segundo a OMS, cerca de $80 \%$ dos casos de morte por suicídio, em 2016, ocorreram em países de baixa e média renda (WHO, 2018a). Neste período, foram mais de 800 mil mortes por suicídio no mundo, enquanto foram registrados 477 mil homicídios e 180 mil mortes diretas decorrentes de guerras ou conflitos (Dupuy et alii, 2018; Pettersson \& Eck, 2018; WHO, 2018c). Sem prejuízo do valor apresentado, essas mortes apresentam as maiores divergências estatísticas. Independentemente da fonte, os dados incluem os conflitos armados com pelo menos 25 óbitos diretos, no mesmo ano civil, com ou sem a presença do Estado, como uma das partes (até mil mortes, denomina-se conflito, acima de mil, considera-se guerra) e não incluem as mortes causadas por intervenções legais (Muggah, 2015).

Em outras palavras, em um mesmo período, 94 pessoas morreram de suicídio a cada hora, enquanto outras 50 foram assassinadas e 21 foram vítimas diretas de guerras e conflitos armados. Foram quase 4,5 vezes mais vítimas de suicídio e 2,6 vezes mais vítimas de homicídio, do que vítimas de guerras e conflitos armados em um ano. Vale ressaltar que as mortes causadas por guerras e conflitos mais que dobraram em relação ao lustro anterior, e a totalidade das mortes deu-se em países de baixa e média renda (WB, 2018a; WHO, 2014a; 2017).

Como a maior parte da população mundial $(83,41 \%)$ encontra-se nos países de baixa e média renda (WB, 2018b), faz-se necessário esclarecer que a concentração dos casos de mortes por suicídio se mantém, mesmo em números relativos (casos por 100 mil habitantes), variando apenas nos países que apresentam os maiores coeficientes (Värnik, 2012). 
Os países de baixa e média renda apresentaram também uma elevada concentração proporcional de casos de homicídio (78,02\%), no período citado (WHO, 2017). Essa concentração, contudo, não é recente e diferentemente do significativo aumento das taxas de suicídio, as taxas de homicídio apresentaram um decréscimo de 16\%, globalmente, nos últimos 15 anos. Contudo, a redução foi menor em países de baixa e média renda (12\%) do que nos países de alta renda (39\%) (WHO, 2014a).

Os países de baixa e média renda também concentram cerca de $92 \%$ das mortes causadas por acidentes de trânsito (Nantulya \& Reich, 2003; WHO, 2016). Esses casos, anteriormente analisados como acidentais, dada a sua natureza (Krug et alii, 2000; Mascarenhas et alii, 2011), e avaliados por seu significativo impacto no serviço de saúde (Hofman et alii, 2005), são atualmente reconhecidos como evitáveis e não randômicos (Jeffry P. Mckinzie, 2014). De fato, recentes estudos, baseados na concentração de casos por acidentes de trânsito em países de baixa e média renda, demonstraram que analisar as condições socioeconômicas e a correlação de causas externas de morte na determinação dos fatores de risco é mais efetivo na elaboração de ações de prevenção (Denney \& He, 2014; Hofman et alii, 2005; Krug et alii, 2000; Nantulya \& Reich, 2003).

As causas de morte são divididas entre naturais e não naturais. As mortes por suicídio, homicídio e acidentes (quedas, afogamentos, acidentes de trânsito, de trabalho entre outros) são consideradas causas externas de morte ou não naturais de morte, conforme a Classificação Internacional de Mortes (CID ou ICD - International Classification of Diseases) e são subdivididas em violentas (intencionais) ou acidentais (não intencionais).

De acordo com os últimos dados registrados pela OMS sobre as causas externas de morte (WHO, 2018b), essas mortes corresponderam a quase $9 \%$ do total dos óbitos registrados nos países de baixa e média renda, enquanto nos países de alta renda corresponderam a cerca de $6 \%$ do total, conforme pode ser observado na Tabela 1, abaixo.

Foi observado que quando as taxas de causas externas de morte superam aquelas por causas naturais, significa que ambos os tipos de mortes podem ter uma mesma raiz causal (Chon, 2018). Em um levantamento sobre a realidade britânica entre 2007 e 2009, para cada causa externa de morte ocorrida e sua causa registrada como básica, outros mais de 100 mil casos de morte de qualquer natureza foram registrados, tendo a mesma raiz causal como subjacente ou contributiva para a morte ocorrida (Osinowo \& Verne, 2011). 


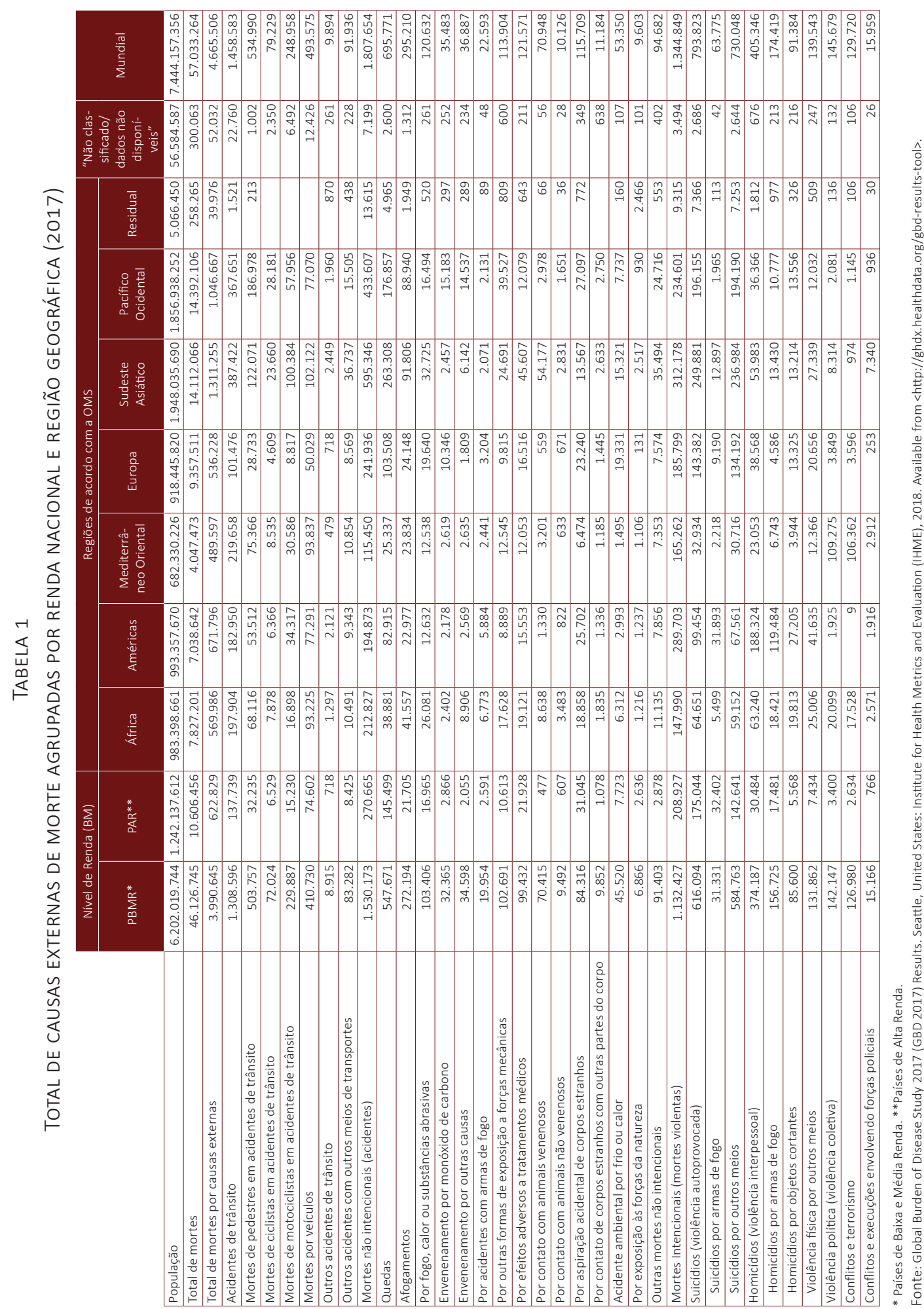


Para a OMS, tanto óbitos relacionados a causas naturais não comunicáveis (como ataques de coração ou câncer), quanto causas externas de morte (acidentais ou violentas) podem apresentar uma mesma raiz causal marcada pela depressão, pelo abuso de álcool ou drogas, reflexo de um contexto de violência (WHO, 2014a). Da mesma forma, um contexto socioeconômico historicamente reforçado de privação, desigualdade, vulnerabilidade e instabilidade, além de condições geográficas e aspectos culturais, está associado ao aumento de causas externas de morte e, por conseguinte, torna-se um fator contribuinte para todos os demais casos de morte daquela localidade, mesmo em países de alta renda (Lampert et alii, 2018)

Assim, de modo a desenvolver ações de prevenção mais efetivas, faz-se necessário a avaliação do perfil da mortalidade de uma determinada região e a associação entre as diferentes causas de morte, para compreender a raiz causal de múltiplos casos de mortes evitáveis, bem como o contexto, marcado pela violência e condição socioeconômica desigual, que, historicamente, mata mais uns do que outros (Bantjes et alii, 2016).

A epidemiologia crítica baseia essa avaliação em três categorias básicas - a determinação social da saúde, a reprodução social e o metabolismo sociedade/natureza, que, juntas, compõem o referencial teórico que visa discutir a abrangência dos efeitos da acumulação do capital na coletividade, bem como seu caráter histórico e social, visando explicá-lo pela relação entre os aspetos biológico e social (Breilh, 2013).

Assim, com base nessas categorias, os estudiosos da área de epidemiologia crítica buscam explicar os efeitos da expansão da acumulação de capital a partir do ponto de vista econômico, político e social, por meio de mecanismos tecnológicos e culturais; da apropriação assimétrica dos recursos vitais (terra, água e genoma); bem como da desigualdade inerente às relações sociais, referentes ao modo de viver, que marcam diferentemente os grupos sociais - tanto por renda e condição econômica (assalariados, os que vivem em situação precária, os pequenos produtores, a classe média), quanto por questões biológicas e culturais (as mulheres, os não brancos) (Barreto, 2004).

\section{Metodologia}

Fonte de dados: a revisão sistemática foi realizada em duas etapas, sendo a primeira exploratória, entre 18 de setembro de 2018 e 13 de dezembro de 2018, e a segunda entre 16 de dezembro de 2018 e 6 de março de 2019. Na primeira etapa, foram analisados 18 bancos de dados (Arca; Assia/ProQuest; Biomed Central; B-On; BVS; Clacso; Cochrane; Ebsco, acesso pela Faculdade de Economia da Universidade de Coimbra; Érudit; Lilacs; Persée; PubMed/Medline; Sage; Scielo; Scopus; Re- 
1. Denomina-se literatura cinza (Laufer, 2007) ou literatura cinzenta (Botelho; De Oliveira, 2015) a literatura institucional, sem o controle de editores científicos ou comerciais. dalyc; Web of Science), e a literatura cinza da Organização Mundial da Saúde e seus organismos vinculados ${ }^{1}$. A pesquisa foi realizada com a associação dos conceitos de "suicídio" e "violência estrutural" e/ou "colonialismo", utilizando conectores de acordo com a lógica de cada base e em cada idioma. Os idiomas utilizados na pesquisa foram espanhol, francês, inglês, italiano e português. O período de publicação selecionado foi de 1968 a 2018 e retornou 578.239 itens.

O período se justifica pelo fato de o primeiro documento da OMS sobre prevenção do suicídio datar de 1968. Àquela altura, estimava-se que mil pessoas ao dia cometiam suicídio e que o suicídio poderia ser evitado com ações voltadas para o sistema de saúde. O texto ressaltava ainda a pouca confiabilidade nas estatísticas e na recolha dos dados (feitas ou pelo sistema de saúde, ou pelo sistema criminal local) (WHO, 1968).

Na segunda etapa, definiu-se uma única equação de pesquisa em inglês, com operadores booleanos: (suicide and "structural violence" and colonial* and democracy and development) or (suicide and "structural violence" and colonial* and democracy) or (suicide and "structural violence" and colonial*) or (suicide and "structural violence"). A pesquisa foi realizada em seis bases/bancos de dados (Arca; Assia; B-On; Clacso/ Rydalic; Ebsco; e Persée), abarcando o mesmo período. Foram selecionados apenas elementos textuais nos mesmos idiomas da etapa anterior, excluindo-se a literatura cinza (para manter apenas os trabalhos de teor acadêmico), e retornou 117.985 itens.

As demais bases foram descartadas pelos seguintes motivos:

i. em sete bases (Biomed Central; BVS; Érudit; Lilacs; PubMed/Medline; Scielo e Web of Science) o conteúdo retornado encontrava-se integralmente replicado nas outras bases de dados;

ii. duas das bases não retornaram nenhum item (Cochrane e Sage);

iii. o acesso, temporário, não estava mais disponível para a Universidade de Coimbra (Scopus); e, por fim,

iv. foi selecionado o banco integrado das bases Clacso e Redalyc.

Estudos selecionados: após a supressão dos textos repetidos (restando 36.575) e da exclusão de artigos estranhos ao tema (restando 26.636), optou-se por selecionar apenas os artigos e textos de livre acesso, restando 536 artigos para análise por apresentarem maior intersecção entre os conceitos definidos previamente, dos quais foram selecionados 21 estudos, conforme os critérios definidos para a inclusão e exclusão expostos no Quadro 1: 


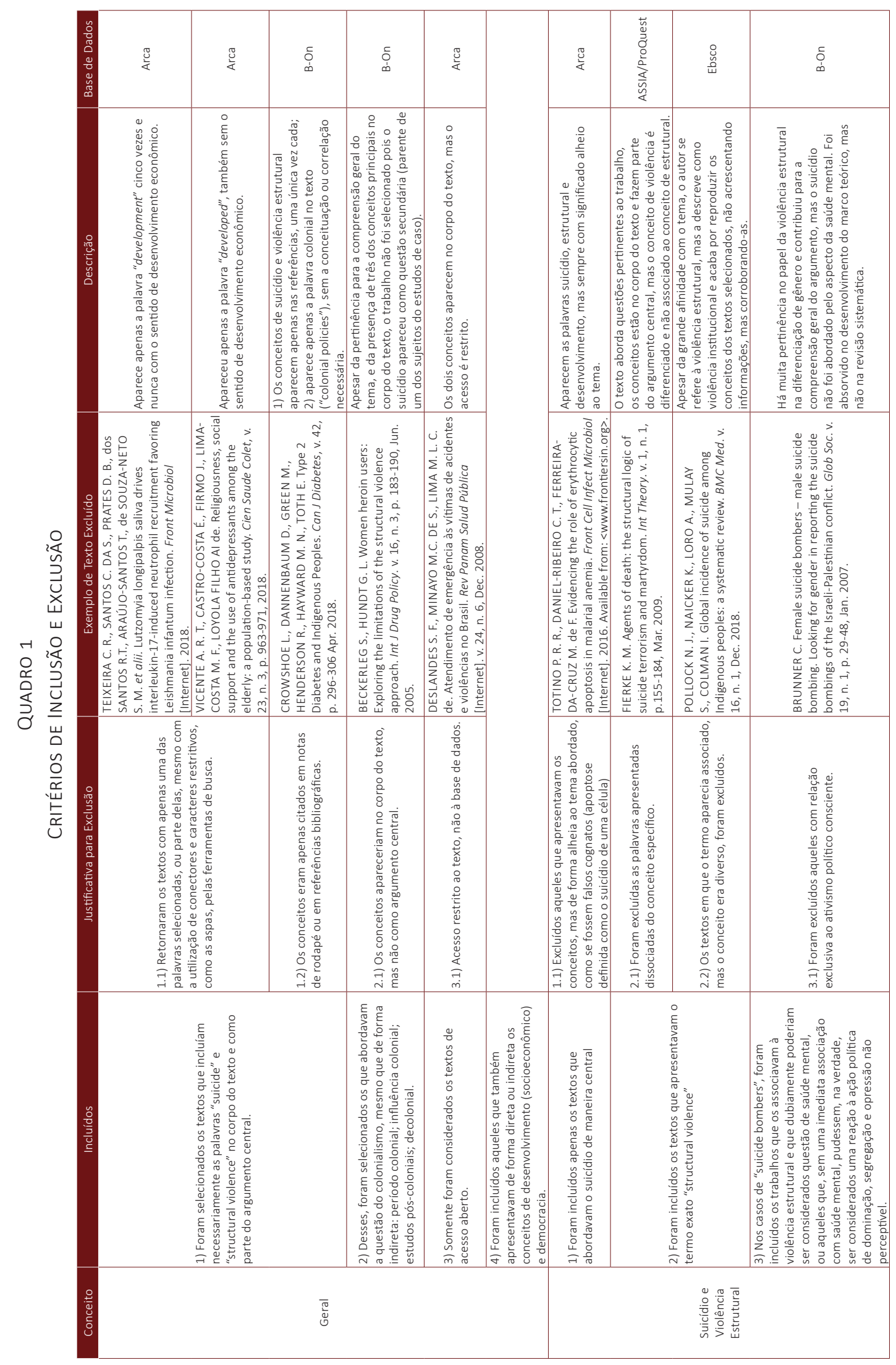

Revista Sociedade e Estado - Volume 35, Número 1, Janeiro/Abril 2020 
Pela Figura 1, a seguir, formulada com base na metodologia Preferred Reporting Items for Systematic Reviews and Meta-Analyses (Prisma), apresenta-se o resumo dos procedimentos adotados na revisão sistemática (McInnes et alii, 2018). Apesar de originalmente utilizada para sintetizar estatisticamente os resultados de estudos primários, por meio de meta-análise, segundo diversos trabalhos na área de saúde entende-se que a metodologia Prisma pode e deve ser utilizada, por analogia, em diferentes tipos de pesquisa e, cada vez mais, recomenda-se seu uso como orientação para a elaboração de estudos de revisões sistemáticas, pelo rigor de seu protocolo, de forma a mitigar o risco de vieses, especialmente em estudos de grupos e fatores de risco (Brasil. Ministério da Saúde, 2014; Galvão et alii, 2015; Mota de Sousa et alii, 2018; Portugal et alii, 2018; Selçuk, 2019).

FIGURA 1

DIAGRAMA PRISMA

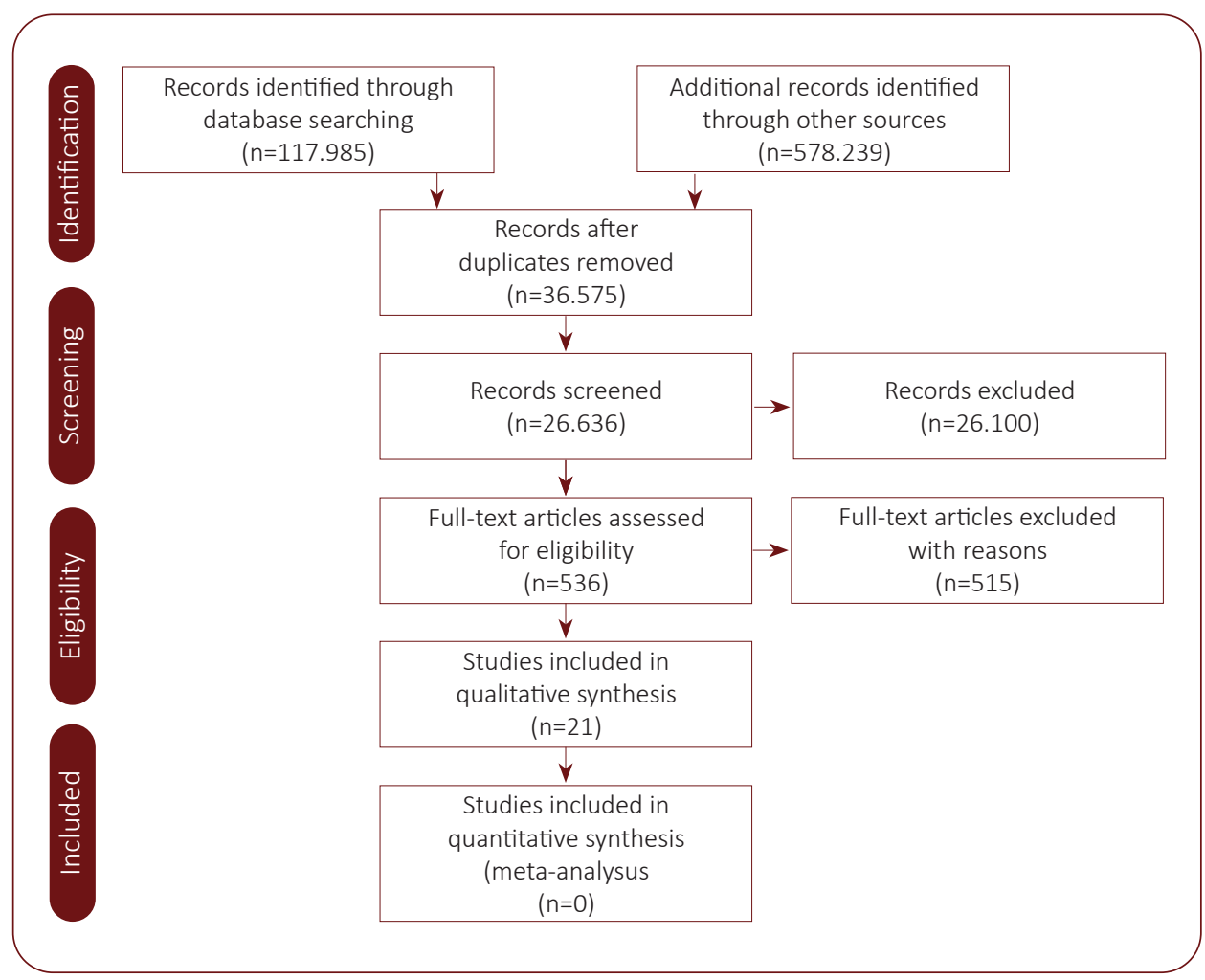

Fonte: Moher, D.; Liberati, A.; Tetzlaff, J.; Altman, D. G. The Prisma Group (2009). Preferred Reporting Items for Systematic Reviews and MetaAnalyses: The Prisma Statement. PLOS Med, 6(7). <e1000097. doi:10.1371/journal.pmed1000097>. For more information, visit: <www.prismastatement.org>. 


\section{Resultados obtidos}

De acordo com o detalhado Quadro 2, observa-se que 38\% dos itens (números 2, $4,7,8,12,14,15$ e 18 do referido quadro) baseiam-se em dados secundários; $24 \%$, em estudos de casos $(3,5,9,11,16) ; 19 \%$ em diferentes tipos de revisões $(1,6,19$, 20); $14 \%$ em estudos teóricos $(10,17,21)$ e $5 \%$ em pesquisa qualitativa (13).

No entanto, em todos esses estudos identificou-se a correlação entre o aumento das taxas de suicídio, em determinados grupos de risco, como consequência da violência estrutural, sendo em $81 \%(1,2,4,5,7,8,9,10,11,12,13,15,16,18$, 19, 20 e 21) desses estudos, de forma direta e, em 19\% (3, 6, 14 e 17), indireta. Em 19\% (1, 13, 16 e 20) dos estudos, essa correlação foi acrescida pela influência do sistema econômico capitalista, sob os conceitos de desenvolvimento tardio e políticas neoliberais, como expressão da violência estrutural, que afeta mais esses grupos de risco.

Em todos os estudos as categorias analíticas de raça e gênero marcaram a identificação dos grupos de risco em contexto de violência estrutural, de forma isolada ou sobreposta entre si - 5\% (item 7) -, ou associada com classe social-20\% (6, 9, 16 e 20 -, e outras condições de vulnerabilidade que atingem grupos específicos, como migrantes - 5\% (3) - e idosos - 5\% (17). De fato, os indígenas apareceram em $48 \%$ dos estudos $(1,2,4,5 ; 12,13,14,18,19$ e 21$)$ e mulheres em $38 \%(3,7,8,11,13$, 14,17 e 18). Os jovens apareceram como grupo de risco em $38 \%$ dos estudos ( 1 , $7,8,10,12,14,18$ e 19) e, desses, sendo os jovens indígenas caracterizados como subgrupo de risco em $63 \%$ (1, 12, 14, 18 e 19); não brancos em $25 \%$ (8 e 10) e jovens afrodescendentes em $13 \%$ (7).

Entre os fatores protetivos mormente identificados para esses grupos de risco estariam:

i. as políticas de diminuição das múltiplas dimensões da desigualdade, sem ferir a valorização e os métodos de produção desses grupos em $48 \%$ dos estudos $(4,5,6,8,9,10,14,15,16$ e 17);

ii. as formas democráticas de governança que propiciem a participação dos grupos de risco no sistema estatal, incorporando as lutas sociais desses grupos à realidade nacional, em $24 \%$ dos estudos $(2,7,8$, 11 e 12);

iii. o fortalecimento comunitário a partir do respeito às tradições dos diferentes grupos étnicos em $24 \%$ dos estudos (1, 4, 8, 16 e 19); e 


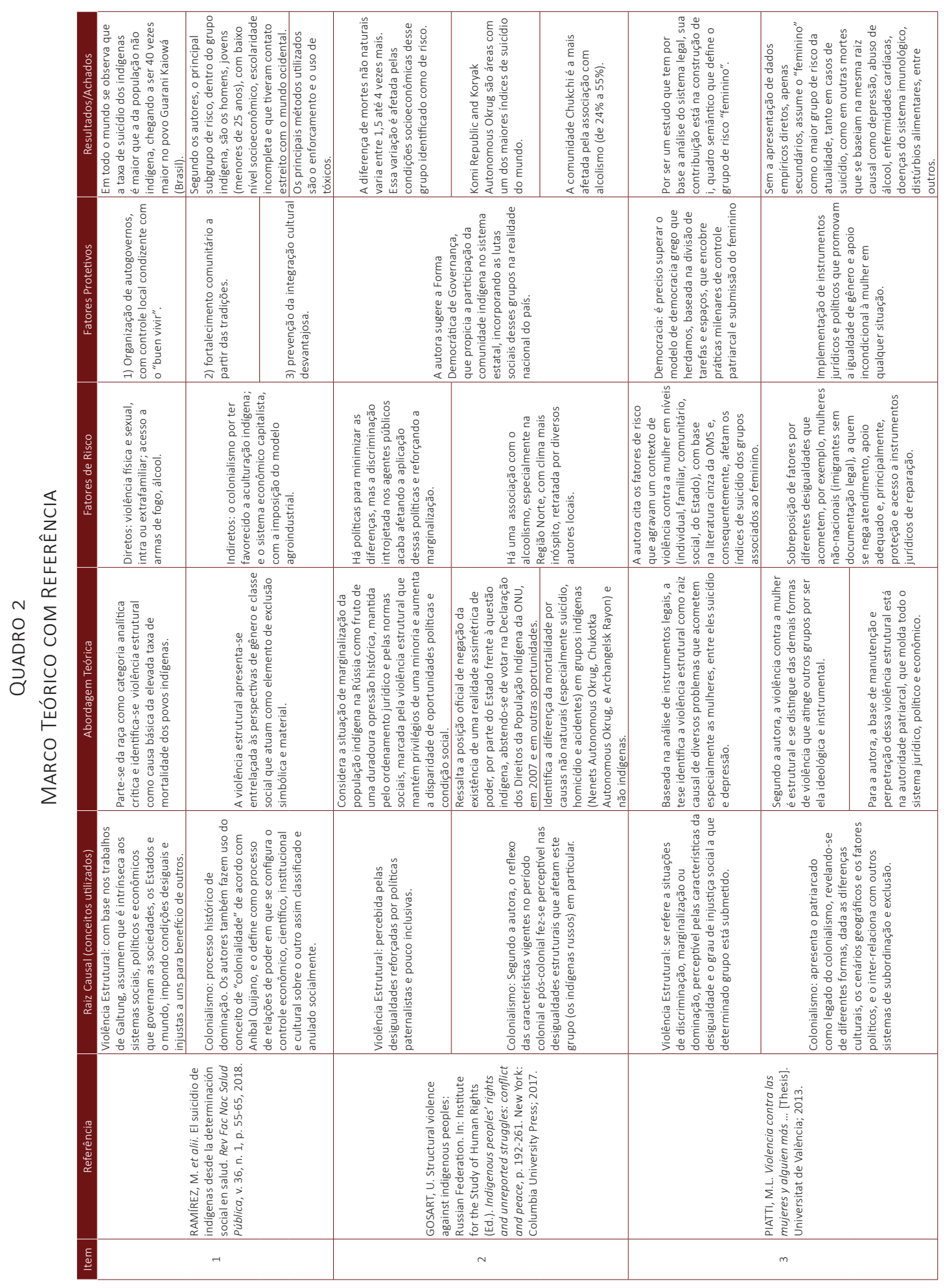




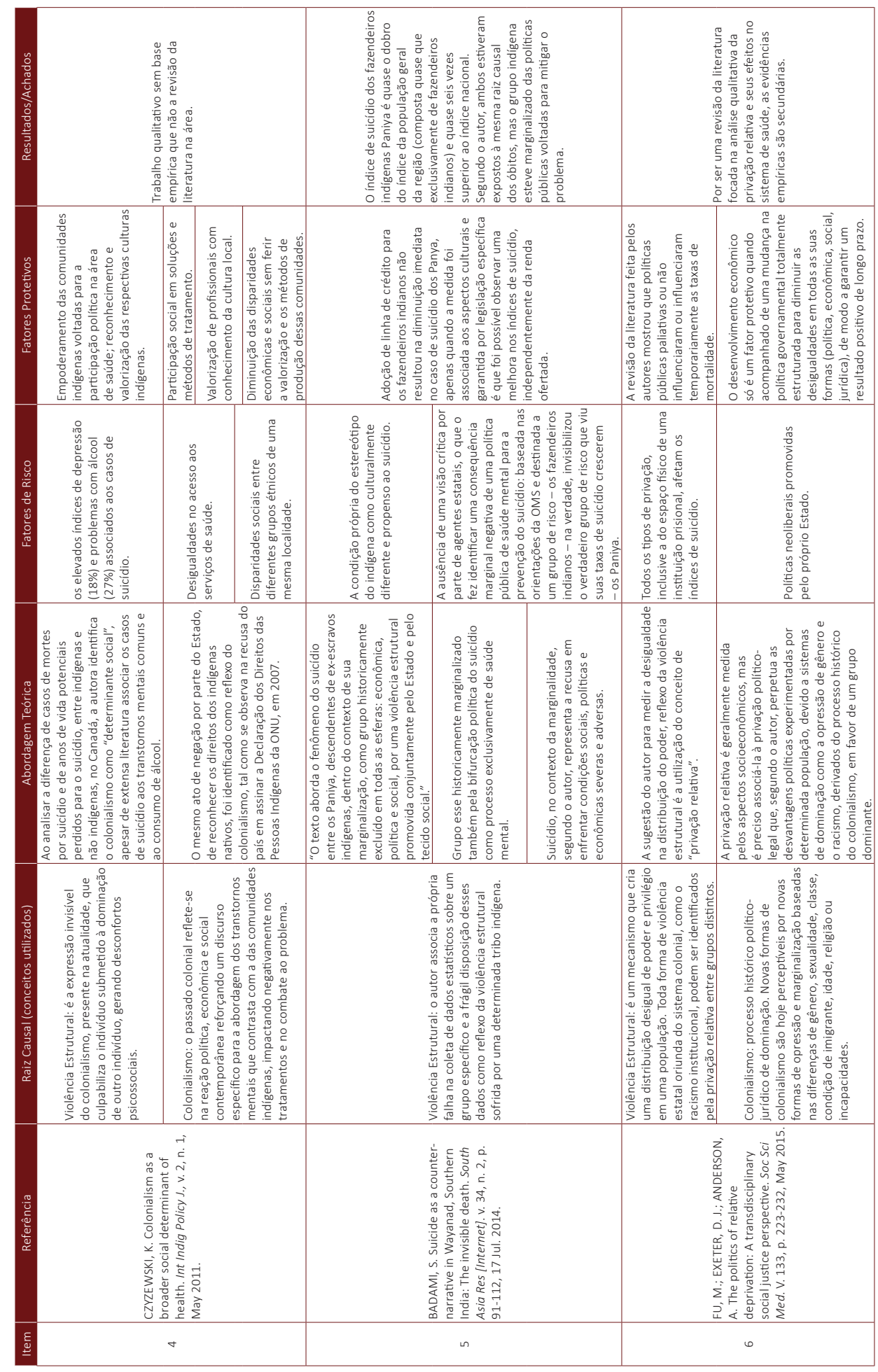




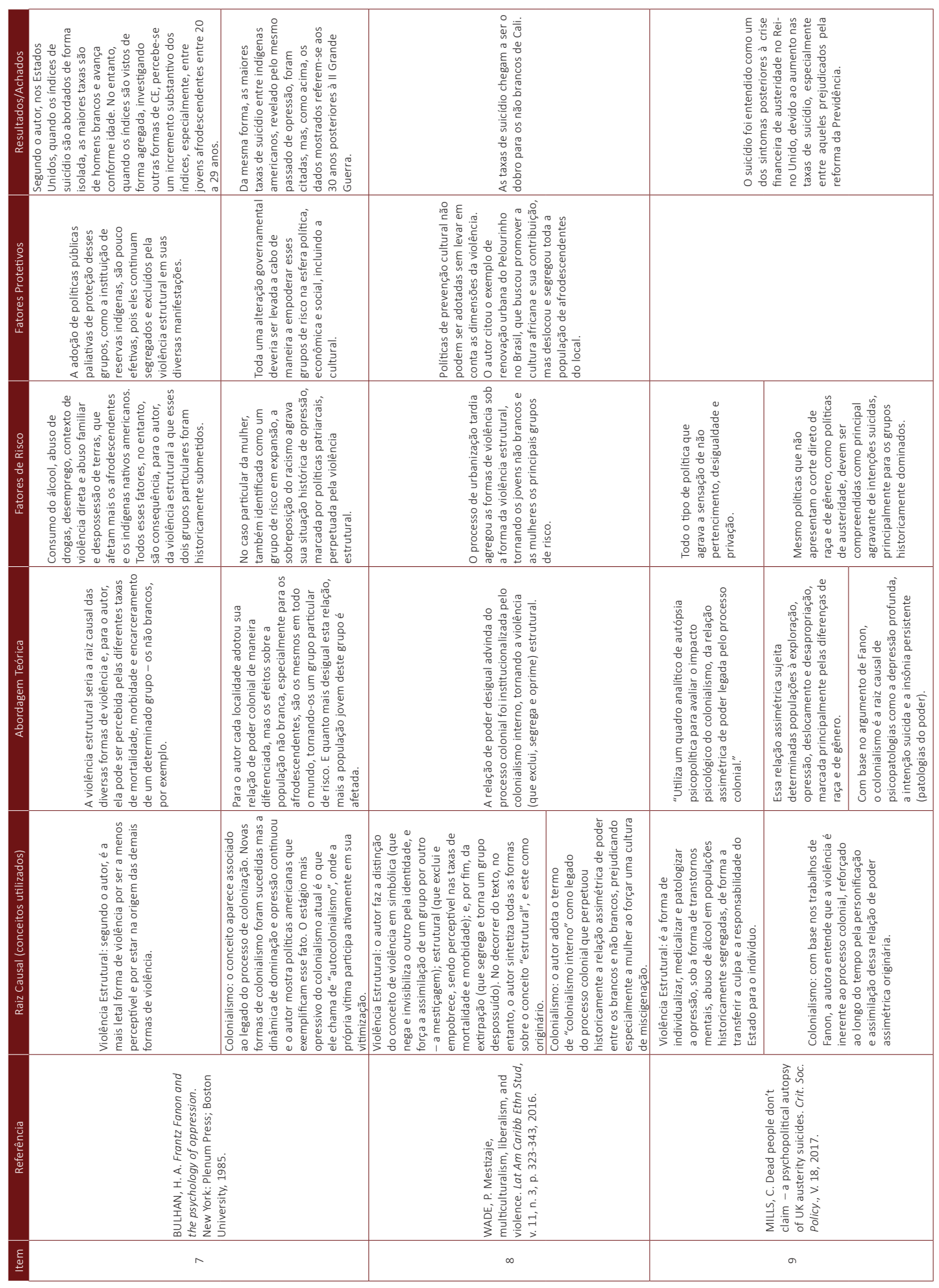




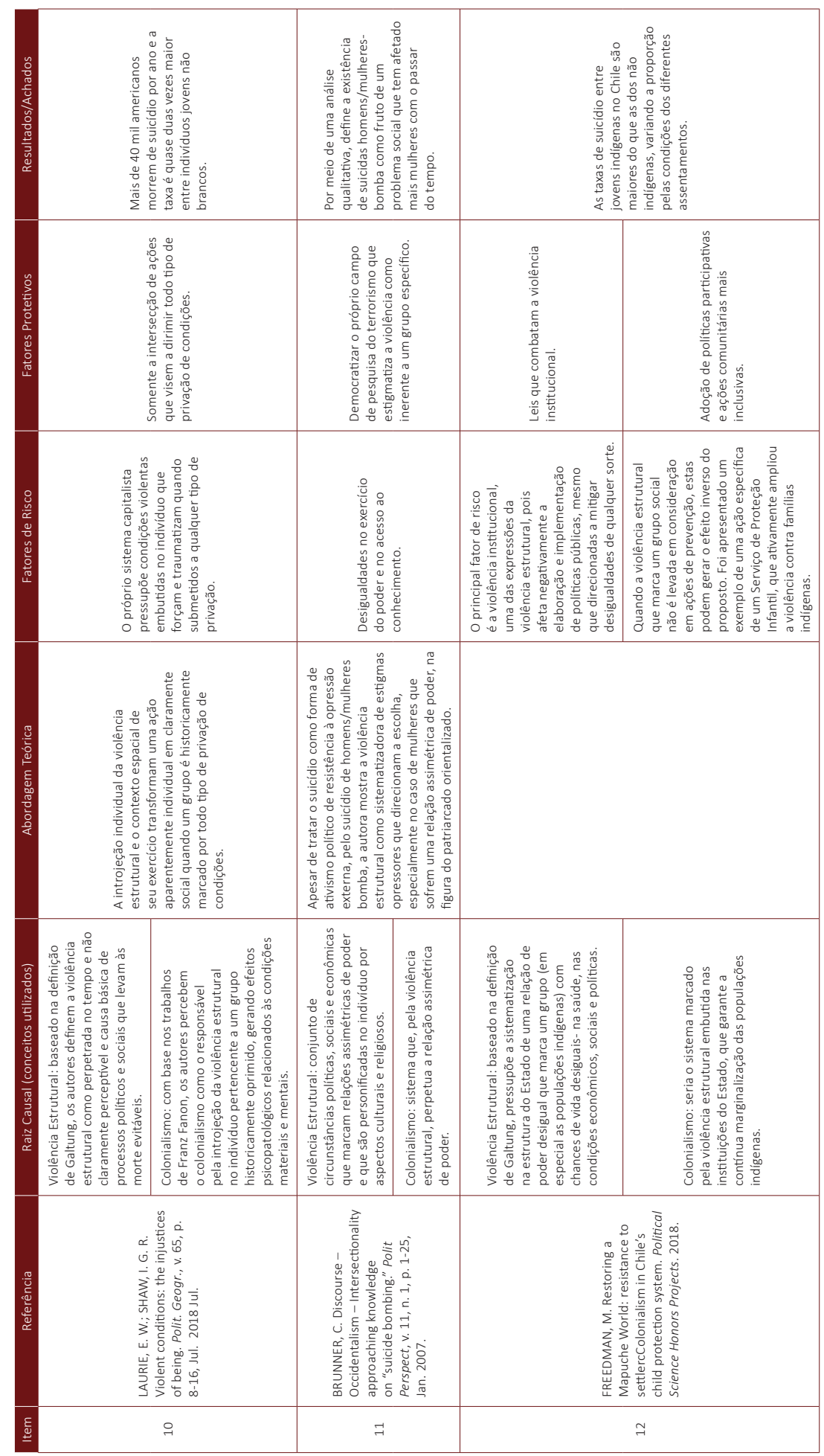




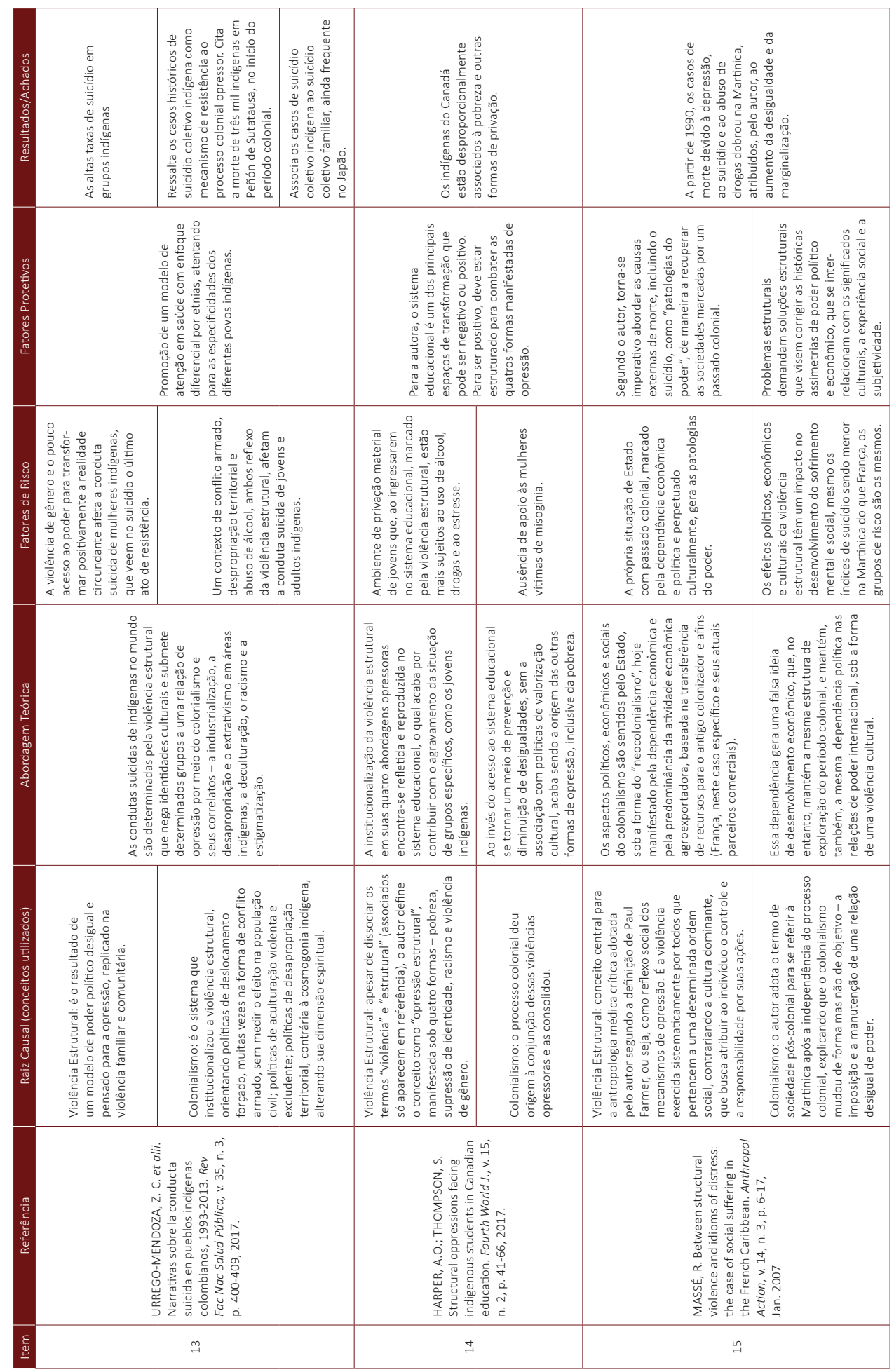




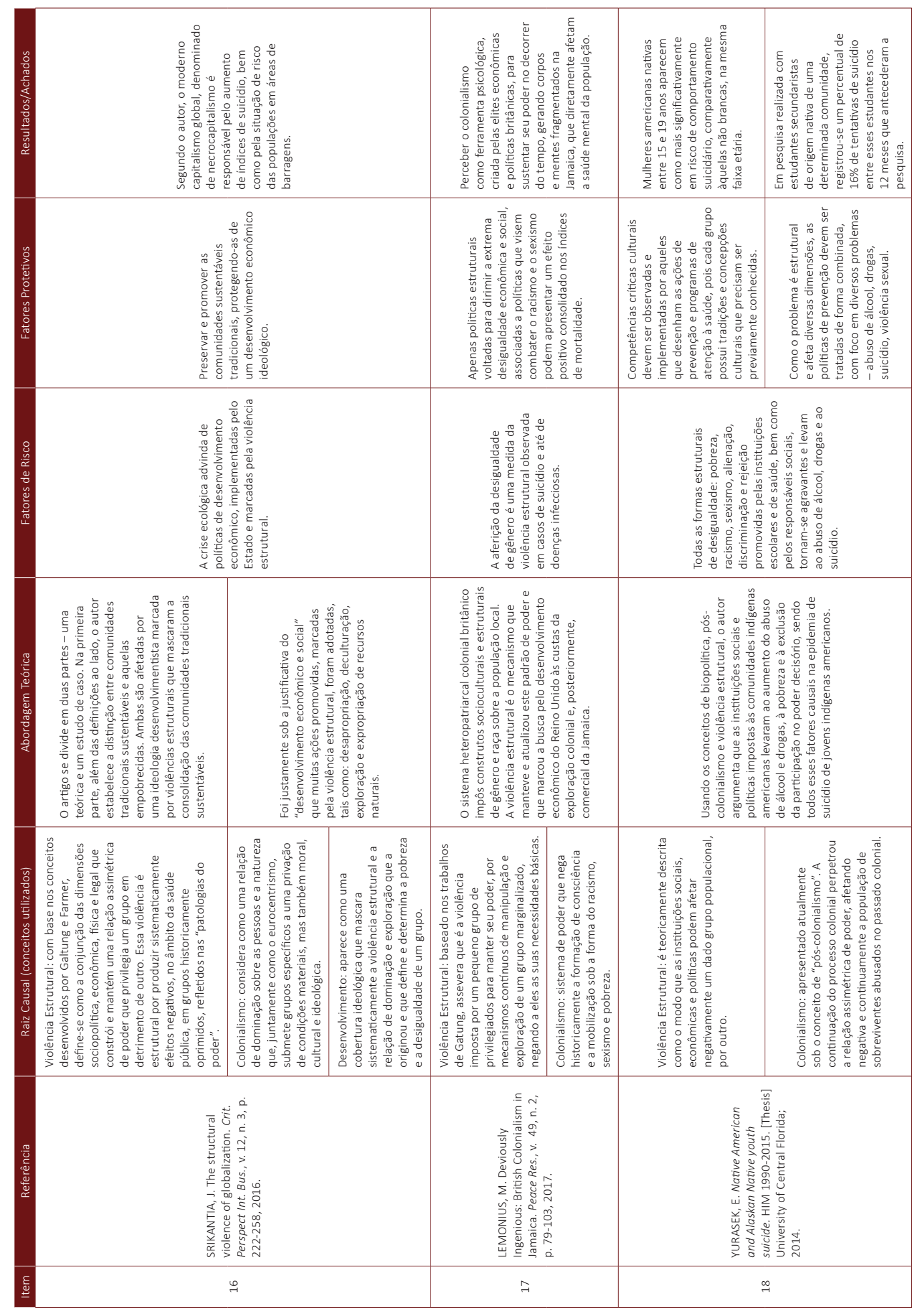




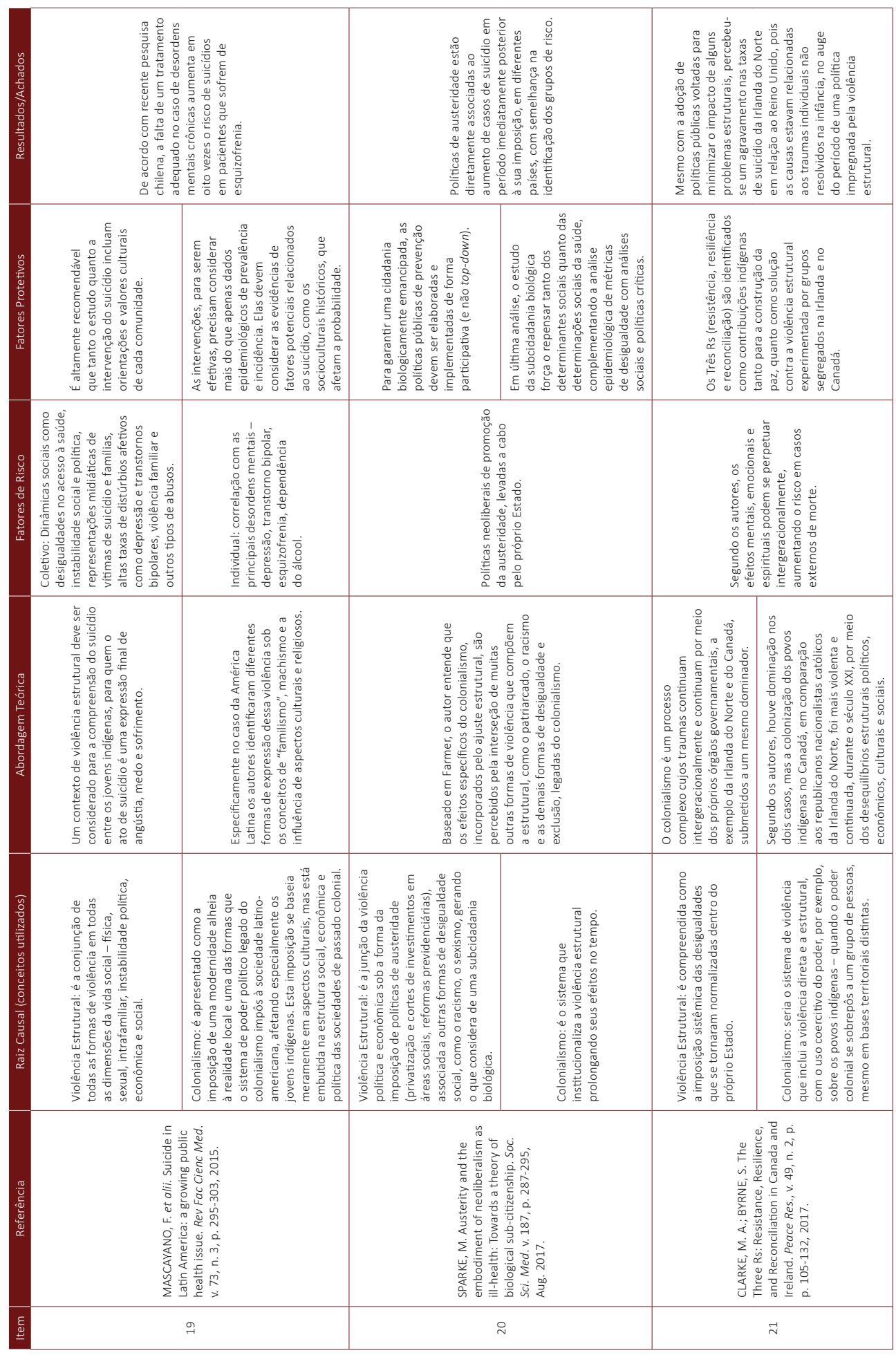


iv. a implementação de instrumentos jurídicos e políticos que promovam a igualdade de gênero, raça e etnia, em $19 \%$ dos estudos (3, 5, 7 e 12).

A revisão sistemática realizada corrobora a alteração no perfil epidemiológico, mas ainda não foi sistematizado um corpo teórico comum condizente com os achados estatísticos, diante da abrangência na definição dos conceitos. Neste sentido, o Quadro 3 apresentará os resultados obtidos dos documentos selecionados e o enquadramento dado pelas autoras e pelo autor, a partir dos conceitos utilizados.

\section{Discussão}

As primeiras correlações para o enfrentamento global do fenômeno do suicídio, promovidas pela OMS, em 1968, foram estabelecidas com as doenças mentais e a dependência ao álcool. Sem indicações ou evidências científicas claras, apresentou-se a premissa de que o suicídio estaria associado a "um pedido de ajuda" e "não a uma vontade de morrer". Não houve menção às diferentes manifestações da violência, nem sob o aspecto da desigualdade, mas ressaltou-se que "pesquisas mostraram que o suicídio em países em desenvolvimento é um problema mais importante do que o anteriormente suspeitado" (WHO, 1968).

Este comentário, mesmo se tratado de forma incipiente, relata o indício de uma transformação do perfil epidemiológico relacionado ao fenômeno do suicídio. Justamente na virada das década 1960 e 1970, a relação entre as etapas do desenvolvimento econômico, da renda nacional e individual e da mudança progressiva no perfil epidemiológico foi estabelecida, com base nos trabalhos de Frederiksen (1969) e Omran (2005).

A partir desses trabalhos, estabeleceu-se a correlação entre o perfil epidemiológico dos países e o correspondente contexto do desenvolvimento econômico. Por um lado, segundo esses autores, as principais causas de morte refletem a fase do desenvolvimento em que determinado país se encontra e, por outro, geram impactos no sistema de atendimento à saúde que necessitam de políticas públicas de longo prazo, de maneira a impedir uma reversão das melhoras alcançadas na qualidade de vida dos cidadãos. Neste sentido, uma tendência de casos em determinado contexto indica a consolidação de uma fase econômica e apontam para seus principais problemas que devem ser enfrentados por essas políticas públicas (Feroz et alii, 2018), conforme Quadro 3, abaixo. 


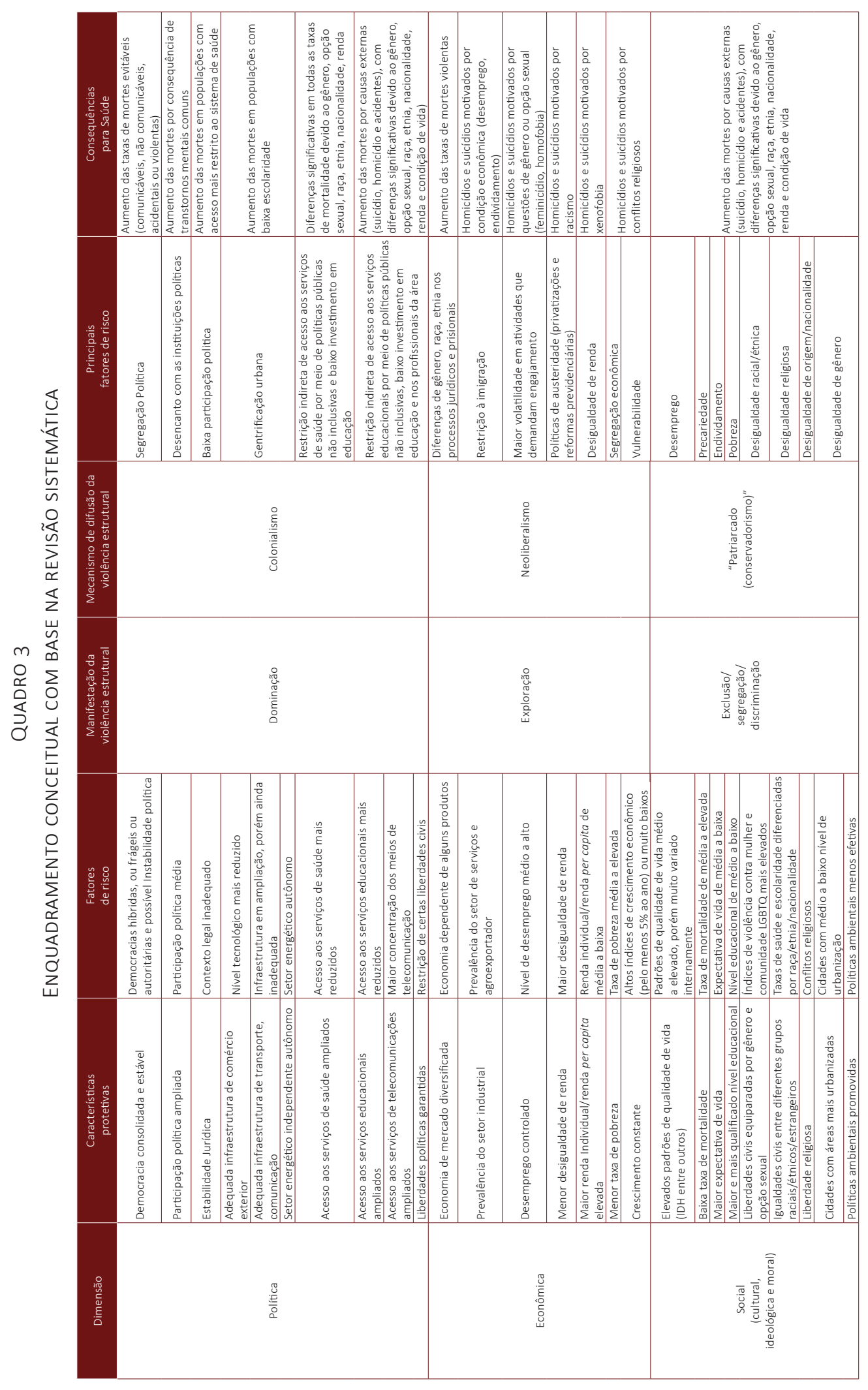


Esses trabalhos identificaram a desigualdade econômica existente e persistente no tempo, a pobreza, a exclusão e as disparidades sociais como problemas e fatores de risco que impactam o perfil epidemiológico local, mesmo em países de desenvolvimento consolidado, influenciados por um contexto de violência.

A violência definida como estrutural foi ressaltada, basicamente nesse mesmo período mas, no âmbito das pesquisas para a paz (Pannenborg, 1979). Apesar de registros anteriores do uso do conceito de "violência estrutural" em textos latino-americanos (Arroyo, 1968), apenas no ano de 1969 a definição do termo é atribuída a Galtung, associada ao conceito de injustiça social perpetrada no tempo por essa violência. $\mathrm{O}$ intuito inicial do autor é definir a paz como ausência de violência, sendo necessário, portanto, especificar a qual tipo de violência ele faz referência (Galtung, 1969).

O termo genérico violência, em si, é um conceito abstrato, dinâmico e contextualizado para Galtung. Como exemplo, o autor cita a morte por tuberculose no século XVIII como pouco relacionável à violência, mas a ocorrência de morte por tuberculose no século $X X$, diante de todo o avanço e os recursos médicos disponíveis no mundo, tem a violência estrutural como causa precípua. Segundo Galtung, as diferentes desigualdades sociais, econômicas e políticas, especialmente a sobreposição delas e a tendência de agravamento das faces da desigualdade, são consequências diretas da violência estrutural, perceptível, por exemplo,

por taxas diferenciais de morbidade e mortalidade entre indivíduos de um mesmo município, entre municípios de uma mesma nação, e entre nações no sistema internacional (Galtung, 1969: 177).

Para o sociólogo norueguês, o agravamento e a concentração de todos os tipos de causas externas de morte refletem o caráter não randômico da distribuição e dos efeitos dessas mortes prematuras e a violência estrutural passa a ser a principal determinante social, a qual o autor já associa aos efeitos do colonialismo (Galtung, 1981a; 1981b; 2005; 2009). Posteriormente, e com base nos trabalhos de Galtung, Paul Farmer afirma haver uma relação direta e causal entre a violência estrutural e a desigualdade de uma minoria, menos predisposta à morte prematura, e uma maioria mais vulnerável aos fatores de risco que levam às mortes evitáveis. Essas - segundo o autor - seriam consideradas "patologias do poder", onde a discriminação e a pobreza aparecem como os principais fatores de risco (Farmer, 2003). Contudo - argumenta Farmer -, é preciso ir além da identificação dos determinantes sociais que caracterizam a matriz de risco dos mais suscetiveis às causas externas de morte, é preciso identificar o mecanismo processual que resulta no efeito patogênico de todas as formas de desigualdades sociais - raça, etnia, gênero, renda, idade (Farmer, 2004; Farmer et alii, 2006). 
A determinação social desse processo baseia-se nos mecanismos de violência cultural e simbólica oriundos do histórico colonial - discriminação, exploração, escravidão e patriarcado. A estrutura incorpora o mecanismo de reprodução tanto da violência direta, originada desse padrão político, quanto indireta, proveniente do padrão econômico dele decorrente - o neoliberalismo - que reforça e legitima um contexto de exclusão e desigualdade, mantendo marginalizado o grupo mais suscetível ao "sofrimento social" (Rylko-Bauer \& Farmer, 2017).

Assim, o processo de determinação social de um contexto de violência estrutural é identificável quando essa violência é julgada como causa das patologias do poder. Em outras palavras, quando estruturas culturalmente marcadas pelas características que envolveram o colonialismo - discriminação e exploração sistemática - estão associadas a um risco maior de mortes evitáveis por um grupo marginalizado, onde a pobreza e todas as formas de exclusão (raça, etnia, gênero, etária) estão entre os determinantes sociais que tornam um grupo social específico (o povo, ou não povo) mais vulnerável.

Desde a instituição da OMS, em 1948 (WHO, 1948a; 1948b), e dos relatos das primeiras reuniões sanitárias internacionais (Paho, 1905), as mortes associadas a um contexto de violência foram tratadas como problema de saúde pública, mas de forma genérica e relacionada a casos isolados (Paho, 1969; WHO, 1958; 1959; 1968; 1974). Sem uma percepção sistematizada sobre os efeitos da violência e sendo muito heterogênea e ampla sua definição, não era possível relacioná-la, adequadamente e de forma científica, aos diferentes casos de morte.

Desde a década de 1960, alguns autores e autoras, que se tornaram mais conhecidos na década de 1980 (Guerrero, 2002), perceberam a violência em suas múltiplas dimensões, suas associações diretas e indiretas com todos os casos de morte, bem como sua relevância como grave problema de saúde pública (Paho, 1990; 1993; 1994; 1995; 1996b; Restrepo, 1994). Justamente, nas discussões da OMS nas Américas é que foram ressaltados conceitos como violência estrutural (Paho, 1994; 1995), violência política, econômica, racial (Paho, 1996b; 1996b), relações de poder desigual e desigualdade de gênero (Paho, 1993; 1997) e a relação de todas as causas externas de morte com um contexto social marcado pela desigualdade, pela privação, pela pobreza e pelo desenvolvimento foram ressaltados (Paho, 1996a; WHO, 1994).

Essa corrente acabou por influenciar o organismo como um todo. Alguns estudos divulgados pela organização passaram a identificar a violência de maneira estrutural, como "expressão de poder, que aumenta a desigualdade social e de gênero" (WHO, 1997a; 1997b), mas ainda de modo intermitente, não constando nas decla- 
rações gerais (WHO, 1997c, 1999a). Somente com a Declaração n.o 49.25, de 1996, a OMS (WHO, 1996) estabeleceu a violência como problema prioritário de saúde pública e definiu o conceito como

\begin{abstract}
o uso intencional de força física ou poder, ameaçado ou real, contra si próprio, outra pessoa ou contra um grupo ou comunidade, que resulta em, ou tem uma alta probabilidade de resultar em ferimentos, morte, danos psicológicos, mau desenvolvimento ou privação (Daher et alii, 2002; Dahlberg \& Krug, 2002; WHO, 1999).
\end{abstract}

Mas o avanço da compreensão do conceito de violência em suas múltiplas dimensões e a inclusão da palavra poder, como uma das formas de manifestação da violência, encontraram resistência e foram consideradas pouco efetivas. Sob a alegação de ser necessário um instrumental mais específico, prevaleceu a influência direta da violência apenas nas causas externas de morte intencionais e a tripartição tipológica destas em:
i. pessoal (suicídio);
ii. interpessoal (homicídio); e,
iiii. coletiva (grandes grupos organizados, Estados ou nações) (WHO, 1999a).

Foi com essa perspectiva que, em 2002, a OMS publicou o primeiro relatório mundial, no qual consolidou essa tipologia da violência e seus correspondentes fatores de risco (WHO, 2002).

De acordo com a OMS, cada um desses tipos de violência apresenta subdivisões por sua natureza ou motivação:

i. a pessoal é subdividida em automutilação (onde não há a intenção inicial de morte, independentemente de sua ocorrência) e comportamento suicida (onde há intencionalidade, independentemente de ocorrer ou não a morte);

ii. a interpessoal é subdividida pelo grau de envolvimento entre a vítima e o agressor, em familiar (maus tratos infantis, violência sexual, abuso contra idosos) e social (homicídios em espaços públicos, como latrocínio nas ruas, homicídios no trabalho, entre outros); por fim, iii. a coletiva, subdivida em política (advinda de guerras e conflitos), econômica (que visam interromper as atividades econômicas) e social (terrorismo). 
Essa tipologia e suas subdivisões podem ter facilitado a coleta de dados e as ações de prevenção paliativas para casos específicos, mas acaba por mascarar a profunda inter-relação entre violência, padrão de poder desigual e perpetração de uma relação social e econômica desigual, que determinam os fatores de risco identificados com os grupos mais vulneráveis por suas condições de gênero, idade, origem étnica ou racial, condição econômica e acesso aos serviços públicos.

Com relevantes exceções, nos estudos de epidemiologia sobre as desigualdades em saúde, prevalecem a análise e as decorrências do contexto desigual e sua relação com a renda (Coburn, 2015; Karlsson et alii, 2010; McCartney et alii, 2013; Pickett \& Wilkinson, 2015; Rambotti, 2015) e outros fatores socioeconômicos, como educação (WHO, 2008), mas não o processo histórico, que reforça esse contexto, bem como as consequências de sua perpetração. Se a determinação social do processo, que originou, mantém e possivelmente agrava essa desigualdade, não for sistematicamente avaliada e dissecada, a interrupção evitável da vida humana de um determinado grupo será sempre maior que a de outro.

A partir de 2014, a OMS publicou novos relatórios em separado sobre suicídio (WHO, 2014b) e violência (WHO, 2014a). Nesses mais de dez anos que separam esses relatórios, a OMS passou, portanto, a tratar separadamente os causas externas de morte e de maneira regionalizada, limitando ou isolando as ocorrências e, consequentemente, minimizando o impacto dessas mortes, além de dificultar a associação com uma raiz causal mais abrangente, como o sistema econômico, por exemplo.

Da mesma forma, para análises do perfil epidemiológico comum aos casos de causas externas de morte, a OMS definiu um critério de associação:

i. pautado na relação direta com a violência, incluindo o homicídio, as guerras e os conflitos (WHO, 2010a; 2010b; 2014a);

ii. a considerar as mortes não intencionais, onde a violência ou não é apresentada, ou aparece como influência indireta (WHO, 2012; 2015); e, por fim,

iii. a examinar o suicídio, manifestação direta de violência, com destaque, na maior parte dos estudos, para a relação do fenômeno com as questões de saúde mental (WHO, 2014b).

De fato, mesmo ressaltando-se a importância dos determinantes sociais nos estudos sobre o suicídio, a corrente dominante da suicidologia ainda se baseia na 
"estatística dos 90\%" (em que 90\% dos casos de suicídio estariam relacionados a problemas de saúde mental). De acordo com esse dado, a relação causal entre suicídio e saúde mental é dada como certa e o ponto de início obrigatório das ações de prevenção. Porém, o significativo aumento de certas taxas nacionais relacionadas à saúde mental e a desproporção do aumento dessas taxas internamente, entre grupos historicamente minoritários, têm revelado a necessidade de reavaliação desse diagnóstico, e da relevância dos aspectos ideológicos e políticos permeados nessa visão dominante do tema (Hjelmeland \& Knizek, 2017).

Como o maior percentual de mortes relacionadas à saúde mental encontra-se nos países de alta renda $(65,2 \%$ - contra $34,8 \%$ nos países de baixa e média renda - e o número de mortes é proporcionalmente pequeno em relação aos demais casos de morte (cerca de 1\% no total global), a atenção ao problema foi, por algum tempo, subdimensionada, especialmente no tocante aos países de baixa e média renda (Patel, 2007). Apenas quando se passou a observar o impacto dos problemas de saúde mental nos demais casos de morte (que chega a 12\%), percebeu-se a necessidade de se reavaliar a associação entre causas externas de morte e saúde mental com a violência estrutural, especialmente observando as desigualdades socioeconômicas (Murray \& Lopez, 1996) e as particularidades sociodemográficas dos países de baixa e média renda, onde o impacto é maior (Maselko, 2017).

Influenciados pelas análises psiquiátricas de Franz Fanon (2007) sobre os problemas de saúde mental no âmbito das guerras coloniais e seus efeitos, China Mills e Bhargavi Davar (2016) entenderam que a concentração e o impacto de questões relacionadas à saúde mental, acompanhada de uma perspectiva global de prevenção, revela um contexto histórico relacionado às origens do colonialismo, em que a psiquiatria serviu como ferramenta ideológica de legitimação da dominação. Essas autoras fazem parte da corrente crítica de pesquisa que investiga as diferentes doenças incapacitantes em países "em desenvolvimento", geralmente associadas à baixa e média renda e geograficamente localizados no Sul Global (Grech, 2009; Grech \& Soldatic, 2016), diante de uma perspectiva global de prevenção promovida e elaborada, muitas vezes, a partir da realidade, das estatísticas e da compreensão de pesquisadores oriundos dos países desenvolvidos.

Essa relação entre suicídio e colonialismo já havia sido ressaltada no I Relatório da OMS, em 2002, a considerar como um dos diversos fatores explicativos da diferença entre as taxas de suicídio dos indígenas da Austrália e do Canadá. O foco do relatório, contudo, recaiu sobre a abrupta confrontação cultural entre diferentes grupos étnicos (WHO, 2002). A questão da diferença cultural apareceu, então, dissociada do padrão de poder desigual, que igualmente afeta as relações de gênero e raça. 
Tal premissa restou evidenciada pelos textos selecionados na revisão sistemática, apresentados no Quadro 2, onde as taxas de suicídio dos não brancos aparecem, ainda, diversas vezes mais elevadas do que as da população não indígena, tanto em países de baixa e média renda como em países de alta renda.

Desde Durkheim o suicídio foi apresentado como dissociado ou afetado de forma diferenciada das demais causas externas de morte pelas condições de renda, uma vez que há um alto índice de suicídio em países de alta renda (Durkheim, 2005). Porém, os atuais dados estatísticos, que indicam a concentração de casos de suicídio em países de baixa e média renda (lemmi et alii, 2016), e mesmo em países de alta renda, nas áreas periféricas marcadas por um contexto de vulnerabilidade (Fazel et alii, 2012; Santana et alii, 2015), demonstram que todas as causas externas de morte podem apresentar a mesma raiz causal, baseada na violência estrutural.

O comportamento das taxas de suicídio, a última das causas externas de morte a se concentrar em países de baixa e média renda, revela, portanto, uma possível interseccionalidade de fatores de risco que necessita de um quadro teórico específico, a identificar certo tipo de violência como causa básica, até mesmo para outros casos de morte, em suas múltiplas formas indiretas - econômica, política e social.

A identificação dos grupos de risco pelo momentum em que as categorias analíticas se cruzam demonstra ser mais efetivo do que abordar as categorias isoladamente, quando se trata de reconhecer e fundamentar os fatores de risco (Carbado et alii, 2013; Crenshaw, 1991).

Considera-se aqui a interseccionalidade das relações de dominação como categoria teórica analítica, desenvolvida inicialmente no contexto das lutas das feministas negras, em que múltiplos sistemas de opressão se baseiam em relações de poder estruturadas sobre as categorias de raça, etnia, gênero, orientação sexual, corpo (enquanto capacitante social), classe e lugar. Essas categorias representam a multidimensionalidade da assimetria de poder oriunda do colonialismo (Grosfoguel, 2012), já identificada por Fanon e que está na base dos estudos pós-coloniais (Santos, 2007). Estes estudos mostram como a violência estrutural nos Estados modernos tem a sua origem nas formas de gerir, silenciar, oprimir e dominar as sociedades colonizadas, traçando assim uma forte simetria entre violência estrutural e colonialismo (Maldonado-Torres, 2007; 2016; Mignolo, 2011; Quijano, 1992; 2009; 2013).

Apenas promovendo políticas e instrumentos jurídicos que ressaltem as condições estruturais do racismo, do sexismo e das violências correlatas que se sobrepõem, 
discriminam e afetam determinados grupos de risco é que se torna possível enfrentar o fenômeno do suicídio para além do foco da saúde mental.

O exemplo salvadorenho da criminalização do suicídio feminicida por indução ou apoio, único caso de legislação sobre o tema no mundo (El Salvador, 2010), é um avanço jurídico alcançado em virtude da identificação da violência estrutural como princípio motivador do crime que não se encerra no ou na suicida, mas que identifica e personifica o opressor externo a ele ou a ela. A constatação de transtornos mentais comuns - como a depressão ou dependência -, nesses casos, fortalece a comprovação de um padrão desigual de poder em detrimento da vítima suicida, não como causa original e intrínseca ao indivíduo (Corradi et alii, 2016).

Mas é possível definir o suicídio como uma patologia do poder de origem colonial? Ou seja, é possível identificar de forma clara a relação entre colonialismo, violência estrutural e suicídio? Pelo histórico da incidência de suicídio no mundo, não. As maiores taxas de suicídio estavam associadas a países de alta renda com desenvolvimento econômico avançado e consolidado, como o Japão (Andrés et alii, 2011) e a Alemanha (Blüml, 2013; 2017); atingia mais os homens do que as mulheres; mais os indivíduos inseridos em um contexto urbano, com maior acessibilidade aos serviços de saúde, do que os da área rural; mais os adultos do que os jovens ou idosos; mais os homens brancos do que não brancos.

A partir de uma análise agregada dos dados, acompanhada pelos Gráficos 1 e 2, essas máximas estariam mantidas ainda hoje. Por que, então, considerar o suicídio como uma patologia do poder?

\section{GRÁFICO 1}

MORTES POR SUICÍDIO POR

RENDA NACIONAL (1990-2017)

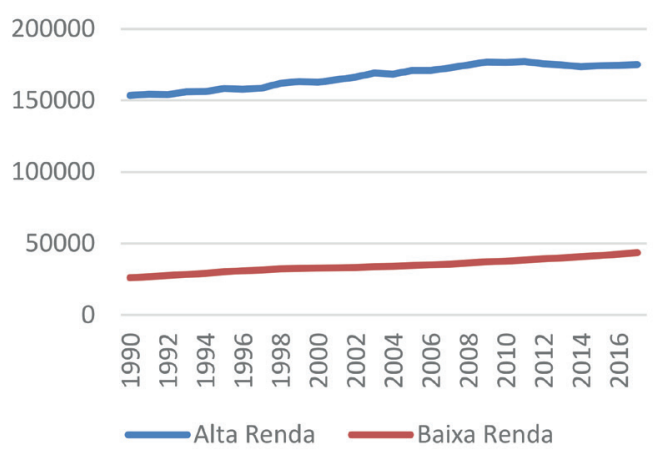


GRÁFICO 2

MORTES POR SUICÍDIO POR SEXO (1990-2017)

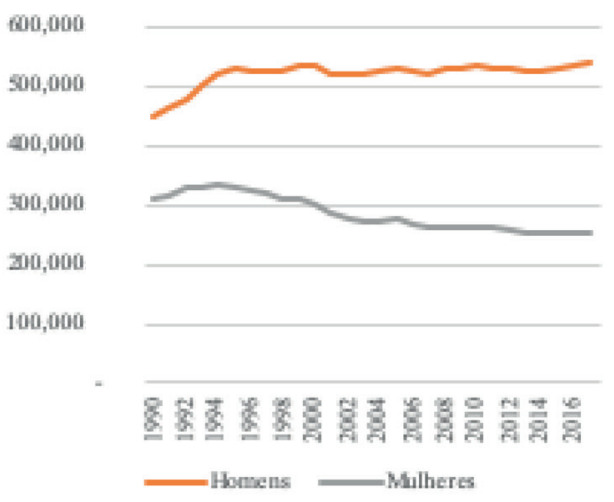

Fonte: Global Burden of Disease Study 2017 (GBD 2017), disponível em: <http://ghdx.healthdata.org/gbd-results-tool>

GRÁFICO 3

MORTES POR SUICÍDIO (TOTAL) POR RENDA MÉDIA (1990-2017)

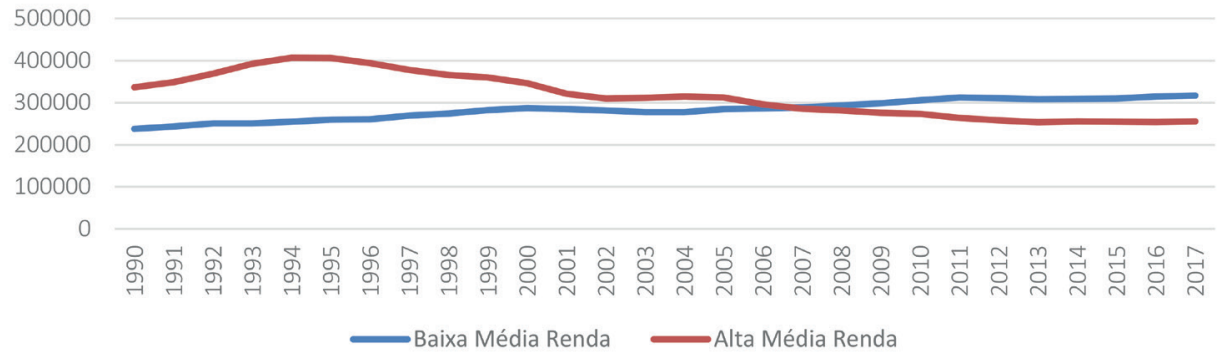

\section{GRÁFICO 4}

RAZÃO HOMEM/MULHER NO TOTAL DE CASOS DE MORTES POR SUICÍDIO (1990-2017)

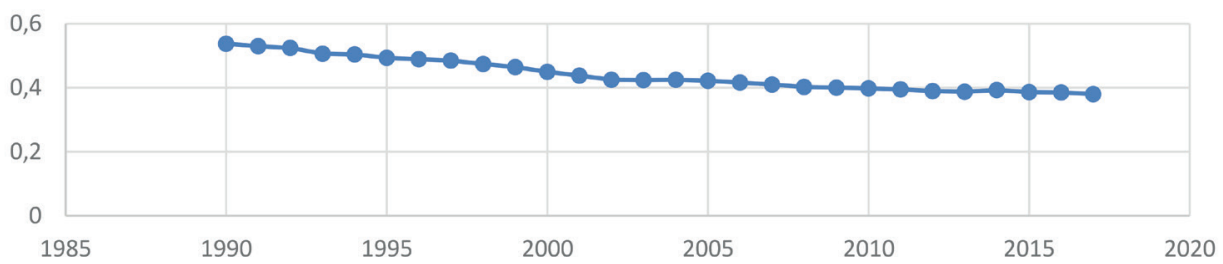

Os casos de morte por suicídio em números absolutos ocorrem mais em países de média renda e aumentaram entre os países de renda média-baixa, em relação aos de renda média-alta, conforme Gráfico 3. Juntos, esses países contaram com mais 
GRÁFICO 5

MORTES (\%) POR SUICÍDIO NA POPULAÇÃO FEMININA (1990-2017)

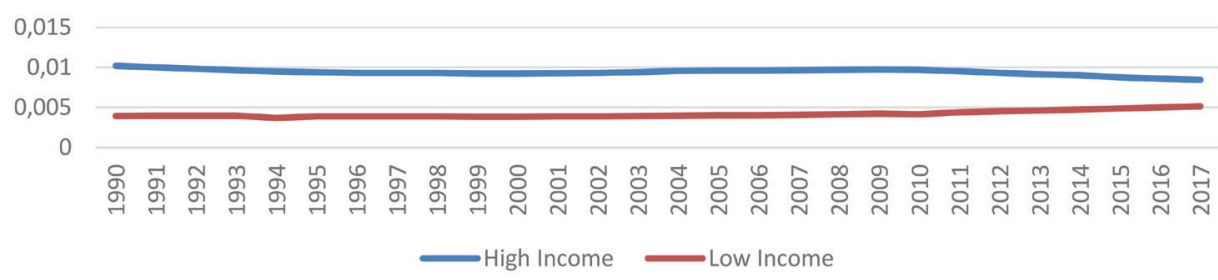

GRÁFICO 6

INCIDÊNCIA (\%) DE CASOS DE SUICÍDIO

POR SEXO EM PAÍSES DE ALTA RENDA (1990-2017)

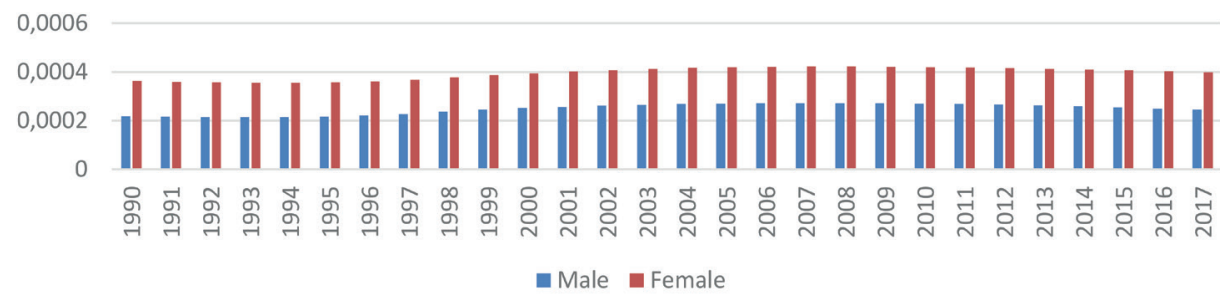

Fonte: Global Burden of Disease Study 2017 (GBD 2017), disponível em: <http://ghdx.healthdata.org/gbd-results-tool>.

de três vezes (3,6 vezes), em média, a quantidade de casos de mortes por suicídio em países de alta renda, nos últimos 30 anos.

A razão do total de mortes por suicídio entre homens e mulheres diminuiu nos últimos 30 anos, conforme Gráfico 4. O percentual de casos de suicídio na população feminina aumentou nos países de baixa renda (PBR), conforme Gráfico 5 e nos países de alta renda a incidência (novos casos), em termos percentuais, foi maior entre a população feminina do que masculina, conforme Gráfico 6.

A incidência de casos de suicídio aumentou globalmente entre 1990 e 2017, especialmente entre as mulheres de 20 a 24 anos. Durante o ano de 2017, nos países de alta renda, a maior razão de incidência de mortes por suicídios ocorreu com mulheres entre 15 e 29 anos e nos países de baixa e média renda, entre os idosos do sexo masculino, conforme Tabela 2, abaixo. 
TABELA 2

Razão de mortes por suicídio sobre o total de óbitos, por renda, sexo e idade (2017)

\begin{tabular}{|c|c|c|c|c|c|c|c|c|c|}
\hline \multirow[b]{2}{*}{ Faixa Etária } & \multirow[b]{2}{*}{ Gênero } & \multicolumn{2}{|c|}{ Alta Renda } & \multicolumn{2}{|c|}{ Alta Média Renda } & \multicolumn{2}{|c|}{ Baixa Média Renda } & \multicolumn{2}{|c|}{ Baixa Renda } \\
\hline & & $\begin{array}{l}\text { Mortes } \\
\text { (TS/TM) }\end{array}$ & $\begin{array}{c}\text { Incidência } \\
\text { (TS/TM) }\end{array}$ & $\begin{array}{l}\text { Mortes } \\
\text { (TS/TM) }\end{array}$ & $\begin{array}{c}\text { Incidência } \\
\text { (TS/TM) }\end{array}$ & $\begin{array}{c}\text { Mortes } \\
\text { (TS/TM) }\end{array}$ & $\begin{array}{c}\text { Incidência } \\
\text { (TS/TM) }\end{array}$ & $\begin{array}{c}\text { Mortes } \\
\text { (TS/TM) }\end{array}$ & $\begin{array}{c}\text { Incidência } \\
\text { (TS/TM) }\end{array}$ \\
\hline \multirow{2}{*}{10 a 14} & Mulher & 0,63 & 121,83 & 1,06 & 33,32 & 1,47 & 16,57 & 0,62 & 14,80 \\
\hline & Homem & 1,18 & 32,35 & 1,35 & 16,26 & 1,39 & 9,36 & 1,66 & 9,68 \\
\hline \multirow{2}{*}{15 a 19} & Mulher & 3,39 & 380,79 & 3,17 & 61,83 & 11,11 & 55,93 & 2,59 & 35,36 \\
\hline & Homem & 9,30 & 136,59 & 6,86 & 37,41 & 6,98 & 27,24 & 5,29 & 28,72 \\
\hline \multirow{2}{*}{20 a 24} & Mulher & 5,03 & 473,83 & 3,22 & 56,49 & 14,04 & 83,32 & 3,27 & 41,67 \\
\hline & Homem & 18,47 & 221,54 & 11,91 & 44,22 & 15,89 & 43,53 & 10,75 & 41,00 \\
\hline \multirow{2}{*}{25 a 29} & Mulher & 5,84 & 378,74 & 4,24 & 41,89 & 12,74 & 66,24 & 3,52 & 33,27 \\
\hline & Homem & 20,48 & 216,83 & 14,13 & 42,18 & 17,75 & 48,85 & 12,05 & 40,61 \\
\hline \multirow{2}{*}{30 a 34} & Mulher & 6,73 & 331,51 & 4,38 & 35,80 & 9,74 & 45,88 & 3,75 & 26,93 \\
\hline & Homem & 21,38 & 192,72 & 15,47 & 41,52 & 19,75 & 48,18 & 12,60 & 38,83 \\
\hline \multirow{2}{*}{35 a 39} & Mulher & 7,40 & 320,88 & 4,20 & 35,19 & 9,39 & 39,42 & 4,86 & 25,30 \\
\hline & Homem & 22,62 & 179,63 & 15,70 & 41,67 & 20,00 & 47,96 & 15,04 & 41,14 \\
\hline \multirow{2}{*}{40 a 44} & Mulher & 8,39 & 307,16 & 4,43 & 34,39 & 9,38 & 36,01 & 5,43 & 24,38 \\
\hline & Homem & 25,64 & 161,72 & 14,50 & 38,65 & 19,31 & 46,50 & 17,69 & 43,77 \\
\hline \multirow{2}{*}{45 a 49} & Mulher & 9,77 & 264,93 & 5,82 & 30,84 & 8,25 & 30,93 & 7,21 & 23,08 \\
\hline & Homem & 28,93 & 133,21 & 14,89 & 35,62 & 20,23 & 42,53 & 22,39 & 45,44 \\
\hline \multirow{2}{*}{50 a 54} & Mulher & 10,56 & 175,36 & 7,09 & 26,19 & 10,57 & 26,18 & 9,68 & 23,21 \\
\hline & Homem & 31,44 & 98,71 & 16,56 & 34,66 & 19,18 & 39,58 & 28,01 & 49,55 \\
\hline \multirow{2}{*}{55 a 59} & Mulher & 10,29 & 97,40 & 6,52 & 23,82 & 8,61 & 22,61 & 11,31 & 25,02 \\
\hline & Homem & 32,74 & 73,06 & 17,89 & 37,88 & 22,73 & 39,37 & 33,61 & 55,55 \\
\hline \multirow{2}{*}{60 a 64} & Mulher & 9,21 & 61,29 & 9,78 & 27,06 & 9,48 & 21,89 & 13,21 & 27,59 \\
\hline & Homem & 30,27 & 58,40 & 20,55 & 42,33 & 20,89 & 39,66 & 37,50 & 64,06 \\
\hline \multirow{2}{*}{65 a 69} & Mulher & 9,12 & 54,66 & 13,07 & 33,87 & 11,69 & 25,22 & 16,77 & 33,50 \\
\hline & Homem & 28,92 & 55,89 & 25,58 & 52,00 & 23,33 & 42,40 & 48,79 & 80,49 \\
\hline \multirow{2}{*}{70 a 74} & Mulher & 9,67 & 58,41 & 15,95 & 43,51 & 13,78 & 30,74 & 19,90 & 40,19 \\
\hline & Homem & 31,78 & 61,41 & 29,80 & 62,91 & 24,53 & 48,45 & 60,85 & 101,66 \\
\hline \multirow{2}{*}{75 a 79} & Mulher & 10,87 & 65,72 & 20,69 & 57,29 & 15,24 & 37,52 & 22,59 & 45,91 \\
\hline & Homem & 38,28 & 72,40 & 38,92 & 78,31 & 32,16 & 58,83 & 76,08 & 123,65 \\
\hline \multirow{2}{*}{$80<$} & Mulher & 15,29 & 77,19 & 31,77 & 78,40 & 22,67 & 49,42 & 27,24 & 51,99 \\
\hline & Homem & 55,81 & 101,33 & 55,55 & 97,59 & 49,98 & 79,32 & 108,35 & 157,55 \\
\hline
\end{tabular}

\section{Conclusão}

Os estudos apresentados no Quadro 2, apesar da exígua presença de dados primários, puderam ser comparados, com base no protocolo da metodologia Prisma, pela similaridade na identificação de uma mesma raiz causal do fenômeno do suicídio. Pautada na violência estrutural, oriunda do colonialismo, essa raiz atinge grupos de risco específicos, por fatores de risco não associados previamente. 
Um exemplo: os indígenas, anteriormente identificados como grupos de risco em casos de suicídio por questões culturais ou cosmológicas, passaram a ser observados como vítimas da violência estrutural, em contextos assimétricos de poder, em que uma profunda miscigenação, urbanização ou desenvolvimento econômico, não os identifica como tal. Da mesma forma, uma mulher vítima de suicídio pode, na verdade, ser observada como vítima de feminicídio.

Ao associar o colonialismo, o capitalismo, o heteropatriarcado (Santos, 2016) com a violência estrutural como determinações sociais e fatores determinantes na identificação de grupos de risco, tem-se uma nova forma de se abordar o fenômeno social do suicídio.

A sintetização dos resultados e dos conceitos-chave permitiu analisar o processo de concentração de casos de suicídio em países de baixa e média renda como decorrente da determinação social do suicídio, onde princípios democráticos, participativos e inclusivos aparecem como fatores protetivos e a assimetria de poder, a exclusão socioeconômica, a marginalização e a vulnerabilidade social como fatores de risco.

Grande parte dos estudos, provenientes de outras áreas do conhecimento, não aprofundam o que entendem por práticas ou princípios democráticos. Contudo, é possível perceber pela abordagem desses estudos frente aos efeitos do colonialismo - ao focarem na assimetria de poder e na violência estrutural, presente em ações de estados sob regimes considerados democráticos - uma visão crítica do conceito universalizante de democracia (Mignolo, 2014).

Nos estudos de caso apresentados no Quadro 2, por exemplo, entendeu-se que valorizar a cultura indígena é mais do que reconhecer e restringir um grupo a um determinado território, mas incorporar suas perspectivas à construção de práticas sociais e políticas que especificamente os atenda.

No início deste século, alguns estudos epidemiológicos assumiram a possibilidade de relação causal entre o aumento das taxas de suicídio e determinados regimes políticos, de forma mais direta do que fatores socioeconômicos (Blakely \& Coilings, 2002; Page et alii, 2002; Shaw et alii, 2002; Stack, 2002). Em outros estudos, os princípios democráticos avaliados foram os propostos por certos organismos independentes como Freedom House e Democracy Index e apareceram como fatores relevantes sobre a associação entre o regime democrático e as taxas de mortalidade - como o suicídio -, porém com resultados aparentemente opostos (Chon, 2018; Franco et alii, 2004). 
Para uma abordagem típica de intervenção na área de saúde, exige-se a identificação das pessoas com maior probabilidade de serem afetadas e quais seriam os fatores modificáveis que corresponderiam aos riscos ou aos fatores protetivos a que essas pessoas estão submetidas.

Mesmo diante desta literatura, onde fatores político-sociais foram identificados como forças relevantes para o suicídio, apenas fatores de nível individual (como a presença de doença mental) foram constantemente considerados como fatores de risco modificáveis, enquanto os fatores protetivos, mesmo que socialmente considerados, resumem-se ao acesso aos serviços e ao atendimento psiquiátrico e de saúde em geral.

O que os estudos selecionados na revisão sistemática proporcionam, mais do que por um ponto final quanto a possibilidade da correlação entre regime político e taxas de suicídio, é a necessidade de considerar a carga política, econômica e social de problemas comuns processados individualmente como fator de risco, devido a um processo histórico de exclusão e marginalização mantido por um contexto de violência estrutural e que, anteriormente, estavam imiscuídos ao nível individual de risco. O rigor destas análises, portanto, deve identificar histórica e socialmente as raízes desta carga política em suas origens coloniais.

Nesse sentido, é exatamente pela compreensão relacional do suicídio e dos problemas de saúde mental com a violência estrutural, perceptível pelos exemplos específicos dos estudos selecionados e corroborados pela evidência empírica da concentração de casos de morte por suicídio em países de baixa e média renda, que é possível definir o suicídio como uma "patologia do poder", associando-o às consequências de um padrão de poder assimétrico, oriundo do colonialismo.

A revisão sistemática pela metodologia Prisma, ao focar no procedimento de identificação das determinações sociais e não apenas nos resultados específicos, permitiu a construção de um marco teórico que corrobora as observações estatísticas e a sistematização dos conceitos apresentada no Quadro 3.

Os dados acima - associados aos apresentados nos Gráficos 3, 4, 5 e 6 -indicam uma alteração no perfil epidemiológico das mortes por suicídio em grande parte dos países de baixa e média renda, nos últimos 20 anos, em relação à renda, ao gênero, à faixa etária, à raça, à etnia e à localização, compatível com a etapa do desenvolvimento econômico decorrente do processo histórico colonial.

Não mais homens brancos de condições econômicas elevadas correspondem ao grupo de risco que requer maior atenção. A alteração do perfil, marcada por uma 
assimetria do poder, torna mulheres, idosos, jovens, não brancos, de menor renda, migrantes, residentes em localidades menos urbanizadas, mais vulneráveis e precárias como os principais grupos de risco em casos de suicídio.

Pela apresentação dos "fatores protetivos", citados no Quadro 2, é possível afirmar que não basta a adoção de ações de prevenção que visem garantir e promover a vivência das diversas culturas, sendo necessária a adoção concomitante de políticas públicas inclusivas e da ampliação da participação social desses grupos na formulação e execução de políticas, de forma a dirimir as violências estruturais a que historicamente os grupos de risco estão sendo submetidos.

Da mesma maneira, a adoção de políticas de prevenção centrada nos determinantes sociais que afetam o fenômeno do suicídio por critérios meramente materiais - como renda, privação ou condição social - sem considerar o padrão de poder que os define e mantém excluídos e, que também transpassa as relações de sexualidade, gênero e raça - tende a não ser efetiva de forma estrutural.

\section{Referências}

ANDRÉS, Antonio R.; HALICIOGLU, Ferda; YAMAMURA, Eiji. Socio-economic determinants of suicide in Japan. Journal of Socio-Economics, v. 40, n. 6, p. 723-731, 2011.

ARROYO C., Gonzalo. Las comunidades rebeldes. Respuesta a unas interrogantes. Revista Mensaje, v. 17, n. 170, p. 275-280, 1968.

BANTJES, J. et alii. Poverty and suicide research in low- and middle-income countries: systematic mapping of literature published in English and a proposed research agenda. Global Mental Health, v. 3, p. e32, 13 Dez. 2016.

BARRETO, Maurício Lima. The globalization of epidemiology: critical thoughts from Latin America. International Journal of Epidemiology, v. 33, n. 5, p. 1132-1137, 2004.

BERTOLOTE, José Manoel; DE LEO, Diego. Global suicidemortality rates-a light at the end of the tunnel? Crisis, v. 33, n. 5, p. 249-253, Set. 2012.

BERTOLOTE, José Manoel; FLEISCHMANN, Alexandra. A global perspective in the epidemiology of suicide. Suicidologi, v. 7, n. 2, p. 6-8, 2002.

BLAKELY, T.; COILINGS, S. Is there a causal association between suicide rates and the political leanings of government? Journal of Epidemiology and Community Health, 2002. 
BLÜML, V. Antidepressant sales and regional variations of suicide mortality in Germany. J. Psychiatr. Res., v. 87, 2017.

BLÜML, V. Personality factors and suicide risk in a representative sample of the German general population. PLoS One, v. 8, 2013.

BOTELHO, Rafael Guimarães; DE OLIVEIRA, Cristina da Cruz. Literaturas branca e cinzenta: Uma revisão conceitual. Ciência da Informação, v. 44, n. 3, p. 501-513, 2015.

BRASIL. MINISTÉRIO DA SAÚDE. Diretrizes metodológicas. Elaboração de revisão sistemática e metanálise de estudos observacionais comparativos sobre fatores de risco e prognóstico. Brasília: Ministério da Saúde, 2014.

BREILH, Jaime. La determinación social de la salud como herramienta de transformación hacia una nueva salud pública. Rev. Fac. Nac. Salud Pública, v. 31, n. 1, p. 13-27, 2013.

CARBADO, Devon W. et alii. Intersectionality: mapping the movements of a theory. Du Bois Review, v. 10, n. 2, p. 303-312, 2013.

CHON, Don Soo. Democracy, autocracy, and direction of lethal violence: homicide and suicide. Homicide Studies, 29 Maio 2018.

COBURN, David. Income inequality, welfare, class and health: a comment on Pickett and Wilkinson. Social Science and Medicine, v. 146, p. 228-232, 2015.

CORRADI, Consuelo et alii Theories of femicide and their significance for social research. Current Sociology, v. 64, n. 7, p. 975-995, 9 Nov. 2016.

CRENSHAW, Kimberle. Mapping the margins: intersectionality, identiy politics, and violence against women of color. Stanford Law Review, 1991.

DAHER, Michel et alii. World report on violence and health. Genève $(\mathrm{CH})$ : World Health Organization, 2002.

DAHLBERG, Linda L; KRUG, Etienne G. Violência: um problema global de saúde pública. Relatório mundial sobre violência e saúde, p. 1163-1778. Genève: World Health Organization, 2002.

DENNEY, Justin T.; HE, Monica. The social side of accidental death. Social Science Research, v. 43, p. 92-107, 2014.

DUPUY, Kendra et alii. Trends in armed conflict, 1946-2016. Center for Security Studies. Conflict Trends, n. 5, p. 1-4, 2018. 
DURKHEIM, Émile. Suicide. e-book ed. London: Routledge Classics, 2005.

EL SALVADOR. Decreto no 520 de 25 de noviembre de 2010. Asamblea Legilativa de la República, 2010.

FANON, Frantz. The wretched of the Earth. New York: Grove Press, 2007.

FARMER, Paul E. An anthropology of structural violence. Current Anthropology, v. 45, n. 3, p. 305-325, 2004.

- Pathologies of power. Health, human rights, and the new war on the poor. Princenton (NJ): Princenton University, 2003.

FARMER, Paul E. et alii. Structural violence and clinical medicine. PLoS Medicine, v. 3, n. 10, p. 1686-1691, 24 Out. 2006.

FAZEL, Mina et alii. Mental health of displaced and refugee children resettled in high-income countries: risk and protective factors. The Lancet, v. 379, n. 9812, p. 266-282, 2012.

FEROZ, Anam; KADIR, Muhammad Masood; SALEEM, Sarah. Health systems readiness for adopting mhealth interventions for addressing non-communicable diseases in low - and middle - income countries: a current debate. Global Health Action, v. 11, n. 1, p. 1-6, 24 Jan. 2018.

FRANCO, Álvaro; ÁLVAREZ-DARDET, Carlos; RUIZ, Maria Teresa. Effect of democracy on health: ecological study. BMJ, v. 329, p. 1421-1423, 2004.

FREDERIKSEN, Harald. Feedbacks in economic and demographic transition. Science, v. 166, n. 3907, p. $837-847,1969$.

GALTUNG, Johan. Sobre los efectos visibles e invisibles de la violencia. After Violence: 3R, Reconstruction, Reconciliation, Resolution. Coping With Visible and Invisible Effects of War and Violence, p. 1-14, 2009.

Três formas de violência, três formas de paz. A paz, a guerra e a formação social indo-europeia. Revista Crítica de Ciências Sociais, v. 71, p. 63-75, 2005.

A structural theory of imperialism- ten years later. Millennium: Journal of International Studies, v. 9, n. 3, p. 181-196, 1981a.

. Western civilization: Anatomy and pathology. Alternatives: Global, Local, Political, v. 7, n. 2, p. 145-169, 1981b. 
- Violence, peace, and peace research. Journal of Peace Research, v. 6, n. 3, p. 167-191, 1969.

GALVÃO, Taís Freire; PANSANI, Thais de Souza Andrade; HARRAD, David. Principais itens para relatar revisões sistemáticas e meta-análises: a recomendação Prisma. Epidemiologia e Serviços de Saúde, v. 24, n. 2, p. 335-342, Jun. 2015.

GRECH, Shaun. Disability, poverty and development: critical reflections on the majority world debate. Disability and Society, v. 24, n. 6, p. 771-784, 2009.

GRECH, Shaun; SOLDATIC, Karen. Disability in the global south. The critical handbook, 2016.

GROSFOGUEL, Ramón. The concept of "racism". In: FOUCAULT, Michel; FANON, Frantz. Theorizing from the being or the nonbeing zone. Tabula Rasa, n. 16, p. 79102, 2012.

GUERRERO, Rodrigo. Violence is a health issue. Bulletin of the World Health Organization, v. 80, p. 10, 2002.

HJELMELAND, Heidi; KNIZEK, Birthe L. Suicide and mental disorders: A discourse of politics, power, and vested interests. Death Studies, v. 41, n. 8, p. 481-492, 2017

HOFMAN, Karen et alii. Addressing the growing burden of trauma and injury in low-and middle-income countries. American Journal of Public Health Hofman; Peer Reviewed; Global Health Concerns, v. 95, n. 13, 2005.

HOVEN, C. W.; MANDELL, D. J.; BERTOLOTE, José Manoel. Prevention of mental ill-health and suicide: public health perspectives. European Psychiatry, v. 25, n. 5, p. 252-256, 2010.

IEMMI, Valentina et alii. Suicide and poverty in low-income and middle-income countries: a systematic review xrticle (accepted version) (refereed). The Lancet Psychiatry, v. 3, n. 18, p. 774-783, 1 Ago. 2016.

JEFFRY P. MCKINZIE. Injury and global health. Understanding global health. 2. ed. McGraw-Hill Medical, 2014.

KARLSSON, Martin et alii. Income inequality and health: importance of a cross-country perspective. Social Science and Medicine, v. 70, n. 6, p. 875-885, 2010.

KRUG, Etienne G.; SHARMA, Gyanendra K.; LOZANO, Rafael. The global burden of injuries. American Journal of Public Health, v. 90, n. 4, p. 523-526, 2000. 
LAMPERT, Thomas et alii. Health inequalities in Germany and in international comparison: trends and developments over time. Journal of Health Monitoring, v. 3, p. 1-24, 2018.

LAUFER, Miguel. O que fazer com a literatura cinza? Interciencia, v. 32, n. 1, p. 7-17, 2007.

MALDONADO-TORRES, Nelson. Colonialism, neocolonial, internal colonialism, the postcolonial, coloniality, and decoloniality. Critical terms in caribbean and latin american thought. New York: Palgrave Macmillan, 2016.

- On the coloniality of being: Contributions to the development of a concept. Cultural Studies, v. 21, n. 2-3, p. 240-270, 3 Mar. 2007.

MASCARENHAS, Márcio Dênis Medeiros et alii. Epidemiologia das causas externas no Brasil: morbidade por acidentes e violências. Saúde Brasil, 2010. Uma análise da situação de saúde e de evidências selecionadas de impacto de ações de vigilância em saúde. Brasília: Ministério da Saúde, 2011.

MASELKO, Joanna. Social epidemiology and global mental health: expanding the evidence from high-income to low- and middle-income countries. Current Epidemiology Reports, v. 4, p. 166-173, 2017.

MCCARTNEY, Gerry; COLLINS, Chik; MACKENZIE, Mhairi. What (or who) causes health inequalities: theories, evidence and implications? Health Policy, v. 113, n. 3, p. 221-227, 1 Dez. 2013.

MCINNES, Matthew D. F. et alii. Preferred reporting items for a systematic review and meta-analysis of diagnostic test accuracy studies. JAMA, v. 319, n. 4, p. 388, 2018.

MIGNOLO, Walter D. Democracia liberal, camino de la autoridad humana y transición al vivir bien. Sociedade e Estado, v. 29, n. 1, p. 21-44, Abr. 2014.

- The darker side of western modernity - global futures, decolonial options. London: Duke University Press, 2011.

MILLS, China; DAVAR, Bhargavi. A local critique of global mental health. In: GRECH, S.; SOLDATIC, K. (Orgs.). Disability in the global south, p. 437-451. Cham (CH): Springer, 2016.

MOTA DE SOUSA, Luís Manuel et alii. Revisões da literatura científica: tipos, métodos e aplicações em enfermagem. Revista Portuguesa de Enfermagem de Reabilitação, v. 1, n. 1, p. 45-55, 2018. 
MUGGAH, Robert. Counting conflict deaths. Briefing note to members of the inter-agency and expert group on SDG indicators. London: Cornegie Endowment for International Peace, 2015.

MURRAY, Christopher J. L.; LOPEZ, Alan D. Summary of the global burden of disease. Boston (MA): Harvard University Press, 1996.

NANTULYA, Vinand M.; REICH, Michael R. Equity dimensions of road traffic injuries in low- and middle-income countries. Injury Control and Safety Promotion, v. 10, n. 1-2, p. 13-20, 2003.

NOCK, Matthew K. et alii. Suicide and suicidal behavior. Epidemiologic Reviews, v. 30, n. 1, p. 133-154, 2008.

OMRAN, Abdel R. The epidemiologic transition: a theory of the epidemiology of population change. Milbank Quarterly, v. 83, n. 4, p. 731-757, 1 Dez. 2005.

OSINOWO, Adebowale; VERNE, Julia. External causes of death. London: British Library, 2011.

PAGE, A.; MORRELL, S.; TAYLOR, R. Suicide and political regime in New South Wales and Australia during the 20th century. J. Epidemiol Community Health, v. 56, p. 776772, 2002.

PAN AMERICAN HEALTH ORGANIZATION (PAHO). Reunión del Subcomité Especial sobre la Mujer, la Salud y el Desarrollo. MSD17/FR. Washigton (DC): Paho, 1997.

—. La violencia en las Américas: la pandemia social del siglo XX. Comunicación para la Salud. Washigton (DC): Paho, 1996a.

. Progreso en la ejecución del plan regional de acción sobre violencia y salud. Tema 4.5. CE118/13. Washigton (DC): Paho, 1996b.

Progreso en la ejecución del plan regional de acción sobre violencia y salud. Tema 5.4. CD39/14. Washigton (DC): Paho, 1996c.

- Conferencia interamericana sobre sociedad, violencia y salud. Bol. Oficina Sanit Panam. Washigton (DC): Paho, 1995.

_. Mensaje del Director. Bol Oficina Sanit Panam. Washigton (DC): Paho, 1994.

- Violence and health. Provisional agenda item 5.11. CD37/19. Washigton (DC): Paho, 1993. 
_ Violence: a growing public health problem in the region. Epidemiol Bull., v. 11, n. 2, p. 1-7, 1990.

- Special meeting of ministers of health of the Americas. Final report and speeches. Buenos Aires (AR): Paho, 1969.

Second International Sanitary Convention. Washigton (DC): Paho, 1905.

PANNENBORG, Charles O. A new international health order: an inquiry into the international relations of world health and medical care. Alphen aan den Rijn (NL): Sijthoff \& Noordhoff, 1979.

PATEL, Vikram. Mental health in low- and middle-income countries. British Medical Bulletin, v. 81-82, n. 1, p. 81-96, 6 Fev. 2007.

PETTERSSON, Thérèse; ECK, Kristine. Organized violence, 1989-2017. Journal of Peace Research, v. 55, n. 4, p. 535-547, 18 Jul. 2018.

PICKETT, Kate E.; WILKINSON, Richard G. Income inequality and health: a causal review. Social Science and Medicine, 2015

POMPILI, Maurizio. Suicide: a global perspective. e-book ed. Sharjah (UAE): Bentham Science Publishers, 2012.

PORTUGAL, Adílio Campos et alii. Artigo científico na área de saúde: diretrizes para sua elaboração e avaliação. Revista de Ciências Médicas e Biológicas, v. 17, n. 2, p. 265-271, 2018.

QUIJANO, Aníbal. El trabajo. Argumentos, v. 26, n. 72, p. 145-163, México (DF), 2013.

- Colonialidade do poder e classificação social. In: SANTOS, Boaventura de Sousa; MENESES, Maria Paula (Orgs.) Epistemologias do Sul, p. 72-117.Coimbra (PT): Edições Almedina, 2009.

Colonialidad y modernidad/racionalidad. Perú Indígena, v. 13, n. 29, p. 1120, 1992.

RAMBOTTI, Simone. Recalibrating the spirit level: an analysis of the interaction of income inequality and poverty and its effect on health. Social Science and Medicine, v. 139, p. 123-131, 2015.

RESTREPO, Helena E. Vigilancia epidemiológica de homicidios y suicidios. Bol. Oficina Sanit Panam, v. 120, n. 4, p. 316-324, 1994. 
RYLKO-BAUER, Barbara; FARMER, Paul E. Structural violence, poverty, and social suffering. v. 1. Oxford (UK): Oxford University Press, 2017.

SANTANA, Paula et alii. Suicide in Portugal: spatial determinants in a context of economic crisis. Health Place, v. 35, p. 85-94, 2015.

SANTOS, Boaventura de Sousa. Epistemologies of the South: justice against epistemicide. New York: Routledge, 2016.

—. Más allá del pensamiento abismal. De las líneas globales a una ecología de saberes. La Paz (BO): Clacso, 2010.

- Para além do pensamento abissal: das linhas globais a uma ecologia de saberes. Revista Crítica de Ciências Sociais, n. 78, p. 3-46, 2007.

SELÇUK, Ayse Adin. A guide for systematic reviews: Prisma. Turkish Archives of Otorhinolaryngology, v. 57, n. 1, p. 57-58, 2019.

SHAW, M.; DORLING, D.; SMITH, G. Davey. Mortality and political climate: how suicide rates have risen during periods of conservative government, 1901-2000. Journal of Epidemiology and Community Health, v. 56, n. 10, p. 723-725, 1 Out. 2002.

STACK, S. Political regime and suicide: some relevant variables to be considered. Journal of Epidemiology and Community Health, v. 56, n. 10, p. 727, 1 Out. 2002.

TURECKI, Gustavo; BRENT, David A. Suicide and suicidal behaviour. The Lancet, v. 387, n. 10024, p. 1227-1239, 19 Mar. 2016.

VÄRNIK, Peeter. Suicide in the world. International Journal of Environmental Research and Public Health, v. 9, n. 3, p. 760-771, 2 Mar. 2012.

WORLD BANK (WB). Battle-related deaths (number of people) / Data. Disponível em: <https://data.worldbank.org/indicator/VC.BTL.DETH>. Acesso em: 6 Jan. 2019a.

_. Population, total | Data. Disponível em: <http://data.worldbank.org/indicator/SP.POP.TOTL?name_desc=false>. Acesso em: 6 Jan. 2019b.

WORLD HEALTH ORGANIZATION (WHO). Suicide. Genève (CH): WHO, 2018a. Disponível em: <https://www.who.int/news-room/fact-sheets/detail/suicide>. Acesso em: 21 Out. 2018.

- World health statistics monitoring health for SDGs. Genève (CH): WHO, 2018b. 
— Suicide - fact sheet. Genève (CH): WHO, 2017. Disponível em: <http:// www.who.int/mediacentre/factsheets/fs398/en/>. Acesso em: 4 dez 2017.

. Violence and injury prevention. Provisional agenda item 12. WPR/RC66/7. Genève (CH): WHO, 2015.

_ Global status report on violence prevention. Genève (CH): WHO, 2014a.

_. Preventing suicide. A global imperative. Luxemburg (LU): WHO, 2014b.

- Violence and injury prevention. Regional Committee for The Western Pacific. Resolution WPR/RC63.R3. Manila (PH): WHO, 2012.

_. Injuries and violence. The facts. Genève (CH): WHO, 2010a.

. Violence prevention. The evidence. Genève (CH): WHO, $2010 \mathrm{~b}$.

- Closing the gap in a generation. Health equity through action on the social determinants of health. Commission on social Determinants of Health. Genève (CH): WHO, 2008.

- World report on violence and health. Genève (CH): WHO, 2002.

. Violence and health. Kobe (JP): WHO, 1999a.

- Violence prevention: an important element of a health-promoting school. . Genève (CH): WHO, 1999b.

_. Prevention of violence. Provisional agenda item 13. EB 99/INF.DOC./3. Genève (CH): WHO, 1997a.

. Prevention of violence. Provisional agenda item 19 A50/INF.DOC./4. Genève $(\mathrm{CH})$ : WHO, 1997b.

_. Prevention of violence. WHA 50.19. Genève (CH): WHO, 1997c.

- Resolution n. 49.25. Prevention of violence: a public health priority. Genève (CH): WHO, 1996

. First Inter-American Conference on Society, Violence, and Health. Epidemiological Bulletin. Washington (DC): Paho, 1994.

. Suicide and attempted suicide. Genève (CH): WHO, 1974.

_. Prevention of suicide. Genève (CH): WHO, 1968. 
- Official records of the World Health Organization n. 94. First Report on the WHO 1954-1956. Genève (CH): WHO, 1959.

. First report on the world health situation. Eleventh World Health Assembly. Provisional agenda item 6.2. A11/P\&B/6. Genève (CH): WHO, 1958.

. Official records of the World Health Organization n. 13. First WHO Assembly. Genève (CH): WHO, 1948a.

. Regulation $n$. 1 regarding nomenclature (including the compilation and publication of statistics) with respect to diseases and causes of death. Genève $(\mathrm{CH})$ : WHO, 1948b.

— . Road traffic deaths. Disponível em: <https://www.who.int/gho/road_safety/mortality/en/>. Acesso em: 6 Jan. 2019.

Violence Info - homicide. Disponível em: <http://apps.who.int/violence-info/homicide/>. Acesso em: 31 Jan. 2019.

WHO mortality database. Disponível em: <http://apps.who.int/healthinfo/ statistics/mortality/whodpms/>. Acesso em: 6 Jan. 2019. 